\title{
Investigation on the Creep Failure Mechanism of Sandy Mudstone Based on Micromesoscopic Mechanics
}

\author{
Xinshuai Shi, ${ }^{1,2}$ Hongwen Jing, ${ }^{1}$ Weiqiang Chen $\mathbb{D}^{1,3}$ Yuan Gao, ${ }^{1,4}$ and Zhenlong Zhao ${ }^{1}$ \\ ${ }^{1}$ State Key Laboratory for Geomechanics and Deep Underground Engineering, China University of Mining and Technology, \\ Xuzhou 221116, China \\ ${ }^{2}$ Graduate School of Engineering, Nagasaki University, Nagasaki 852-8521, Japan \\ ${ }^{3}$ School of Mechanical, Aerospace and Civil Engineering, The University of Manchester, Manchester M13 9PL, UK \\ ${ }^{4}$ Department of Civil Engineering, Monash University, Clayton, Victoria 3800, Australia \\ Correspondence should be addressed to Weiqiang Chen; weiqiang.chen@manchester.ac.uk
}

Received 11 January 2021; Accepted 19 July 2021; Published 6 August 2021

Academic Editor: Jinze Xu

Copyright (C) 2021 Xinshuai Shi et al. This is an open access article distributed under the Creative Commons Attribution License, which permits unrestricted use, distribution, and reproduction in any medium, provided the original work is properly cited.

\begin{abstract}
In this paper, scanning electron microscope (SEM) tests and 3D scanning technologies were adopted to investigate the creep failure mechanism of sandy mudstone from a micromesoscopic view. The SEM test results showed that the fracture surface micromorphology of the specimens that suffered creep loading was more fractured and rougher. It was also found by the fractal analysis of the SEM microscopic images that the fractal dimensions of the creep failure specimens were larger than those of the uniaxial compression failure, indicating that the creep damage increased the irregularity and a larger degree of roughness fluctuation. The $3 \mathrm{D}$ scanning technologies combining with the $3 \mathrm{D}$ reconstruction methods proved that the crack expansion path of crept specimens was more complicated, showing a more prominent asperity height and slope angle. Finally, a mesostrain dilating microelement model of the sandy mudstone specimen's fracture surface was proposed to prove that the dilatancy effect would be more pronounced in the creep process.
\end{abstract}

\section{Introduction}

Currently, the long-term response and safety of deep engineering projects, such as nuclear waste disposal, crude oil storage facilities, and deep underground space, have attracted wide attention [1-3]. The characteristics of the surrounding rock are correspondingly changed from steady, small deformations in the shallow part to unsteady and nonlinear large deformations mainly caused by the strong dynamic pressure, the bulging, and the strong rheology in the deep part $[4,5]$. Therefore, understanding creep characteristics of deep rocks is very important for the safety and stability assessment of geotechnical engineering projects and constructions $[6,7]$.

Up to now, lots of investigations have been conducted on the macroscopic creep behaviors and laws of rocks but failed to reveal the creep failure mechanisms from the microscopic perspectives $[8,9]$. In fact, the rock creep process is actually an external macroscopic representation of the microscopic effects of various microscopic fractures under constant loads, such as damage, degradation, reorganization, and slip [10-12]. The internal pore structure and micromorphology of the rock will change during the creep damage, which would further affect the seepage properties. Thus, it can provide a better reference to reveal the rock creep damage mechanism based on the micromesoscopic characteristics of the fracture surface of failed specimens.

With the development of microscopic mechanics and advanced microscopic representation technology, there is a new way to study the microscopic mechanism of rock damage. Many scholars rely on advanced instruments and equipment to explore the rock failure mechanism, such as scanning electron microscopy (SEM), acoustic emission (AE), electromagnetic radiation (ER), digital image correlation methods (DIC), and computed tomography (CT). Moreover, deep learning methods have been used to identify defects nowadays so as to serve for the analysis of failure mechanism of some engineering projects [13-15]. Yang et al. [16] used SEM to analyze the micromorphology of the green schist fracture 
surface after a triaxial creep test and proposed that the mechanism of the creep damage of green schist was the mineral crystal slip and cleavage displacement. Keneti and Sainsbury [17] thought that the microstructural features, including the microcracks, veins, and healed joints, influenced the strength and failure patterns of a rock block. They adopted the SEM images to characterized microscale features of the rock fragments to reveal the strain-burst mechanism. Liu et al. [18] used CT to scan the internal damage evolution process of rocks under uniaxial creep in real time and studied the spatiotemporal evolution of the geometric characteristics of mesocracks. The study shows that the uniaxial creep mechanism of rock causes the initial damage to the interior, which leads to nonuniformity and the localization of rock damage evolution. Kou et al. [19] reconstructed the internal failure characteristics of the failed rock-like materials under the action of both mechanical loads and internal hydraulic pressures by using the 3D X-ray computed tomography. They adopted the fractal dimensional analysis of the $3 \mathrm{D}$ fragments to reveal the coupled hydromechanical fracturing mechanism.

However, most of the research on such microscopic effects remains at the qualitative level, with various speculations and a lack of experimental evidence and theoretical support. In this paper, the microstructure of the fracture surface was firstly analyzed using SEM technologies. The mesodestructive morphology and distribution of mineral particles in the sandy mudstone were numerically processed using digital image processing techniques and fractal theory to quantitatively calculate the fractal dimension of the SEM image fractal box, characterizing microscopic irregularities and roughness. Then, 3D scanning technology was adopted to reconstruct the mesomorphology of the sandy mudstone fracture surface, calculate the mesoroughness characteristic parameters, and quantitatively analyze the mesoroughness characteristics of the sandy mudstone fracture surface. Finally, considering the influence mechanism of the mesoroughness on the mesoshearing effect, a mesostrain-dilating microelement model of the fracture surface of a sandy mudstone specimen was constructed and the calculated mesoroughness parameters, such as the microscopic dilatancy angle and normal dilatancy deformation under uniaxial compression and uniaxial compression multistage creep conditions, were used to characterize the specimen's fracture surface topography.

\section{Laboratory Tests}

2.1. Sample Preparation and Loading Apparatus. The sandy mudstone used in this experiment was taken from the Kouzidong coal mine in Anhui province, China, which is a kind of soft rock with a density of $2.62 \mathrm{~g} / \mathrm{cm}^{3}$. All cylindrical specimens prepared for mechanical tests were cored from one large piece of the sandy mudstone sample with a $50 \mathrm{~mm}$ core diameter and a $100 \mathrm{~mm}$ height. Firstly, three standard specimens were selected for uniaxial testing with a loading rate of $0.01 \mathrm{~mm} / \mathrm{min}$ and the typical stress-axial strain curves were displayed in Figure 1. The average value of elastic modulus for the sandy mudstone samples is 25.47 GPa, the Poisson's ratio is 0.12 , and the uniaxial com-

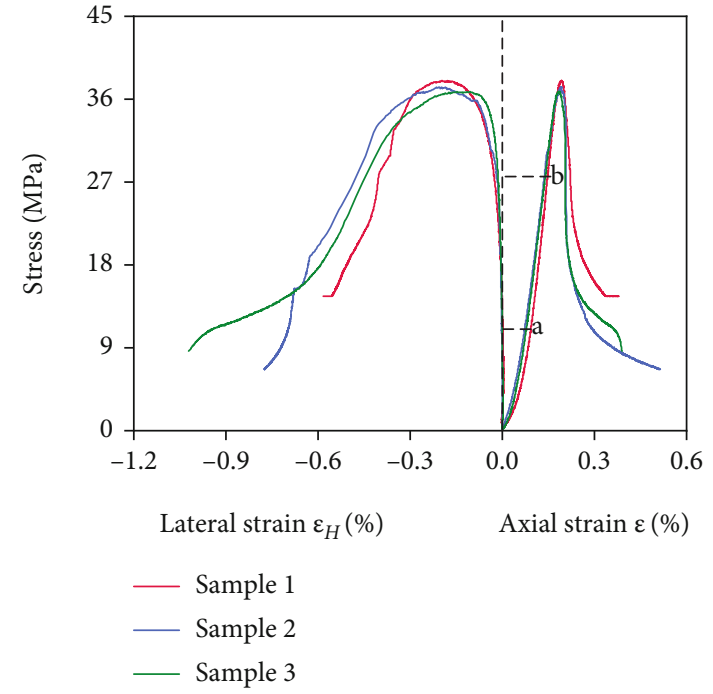

FIgure 1: Uniaxial stress-axial strain curves.

pressive strength is $37.39 \mathrm{MPa}$. Then, the average uniaxial strength was set as the referenced ultimate compressive strength for the creep experiment design. The uniaxial compression multistage creep test scheme for the sandy mudstone samples is shown in Figure 2(a). The sample was axially pressurized to the first stage load with $40 \%$ of the ultimate compressive strength in the uniaxial compression test and then maintained for 24 hours. Then, a $10 \%$ increase at each stage was controlled by displacement with a $0.01 \mathrm{~mm} / \mathrm{min}$ loading rate to reach the target value. It should be noted that before $90 \%$ of the ultimate compressive strength, the loading process was controlled by force, while after that, the test was controlled by displacement. Figures 2(b)-(d) present the axial rheological curves of sandy mudstone specimens. All of the three sandy mudstone samples had creep failure at the 6th stress level of $33.75 \mathrm{MPa}$, which was lower than the average uniaxial compressive strength of $37.39 \mathrm{MPa}$, indicating that the multilevel creep stress path caused the internal damage to the sandy mudstone.

The broken patterns of partially failed specimens under uniaxial compression and rheological tests are presented in Figure 3. To be honest, it is hard to distinguish the macroscopic characteristics of the fracture surface of the failed specimens under different loading paths. However, the microscopic morphological characteristics of the fracture surface of the sandy mudstone can provide more information about the damage evolution of the sandy mudstone specimen during the creep process, including the commonalities and differences of the microscopic damage mechanics mechanism of sandy mudstone under uniaxial compression and creep.

2.2. Micromesoscopic Characterization Techniques. Firstly, a Quanta $^{\mathrm{TM}} 250$ SEM device was used to perform microscopic scanning on the fracture surface of failed sandy mudstone, as shown in Figure 4(a). The device has a maximum magnification of $10^{6}$ times, an acceleration electric field of up to $3 \times 10^{4} \mathrm{~V}$ for the projection electrons, and an effective scanning area of $10 \mathrm{~mm}^{2}$. The SEM image of the original state 


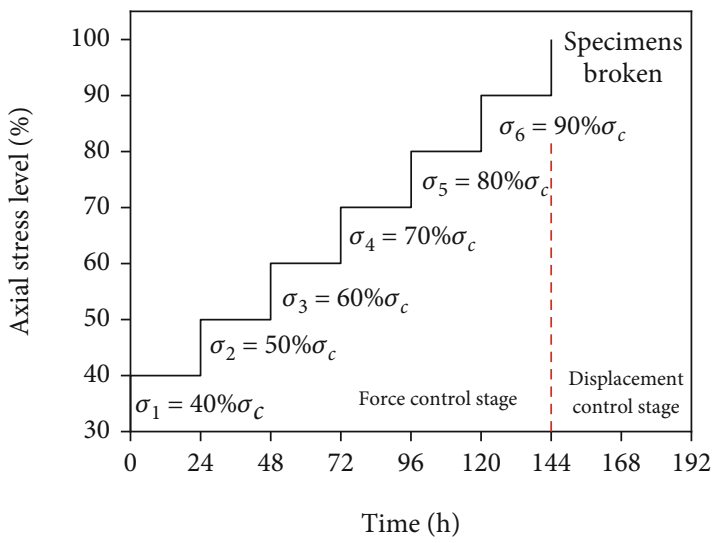

_ Axial stress level (\%)

(a) Step-loading uniaxial rheological test scheme

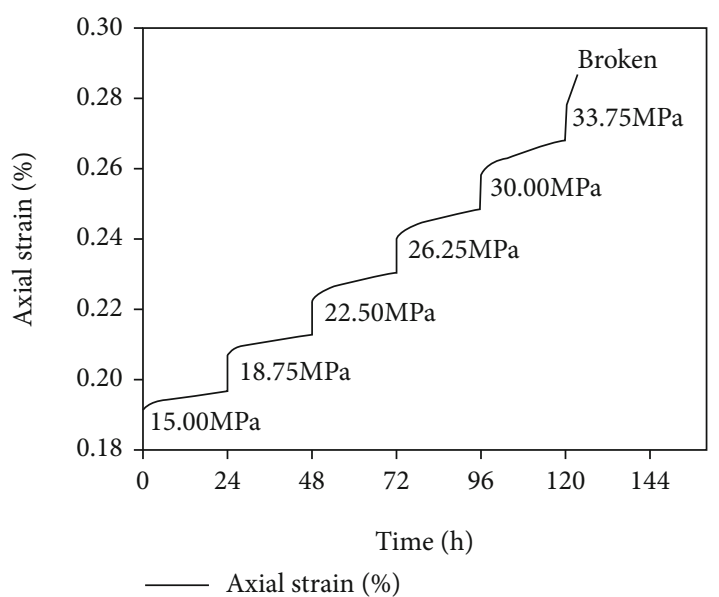

(c) Axial rheological curves of sample \#2

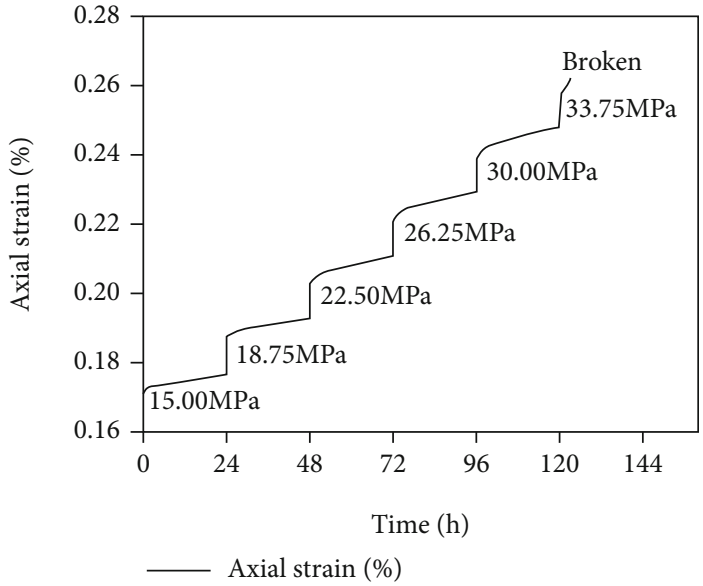

(b) Axial rheological curves of sample \#1

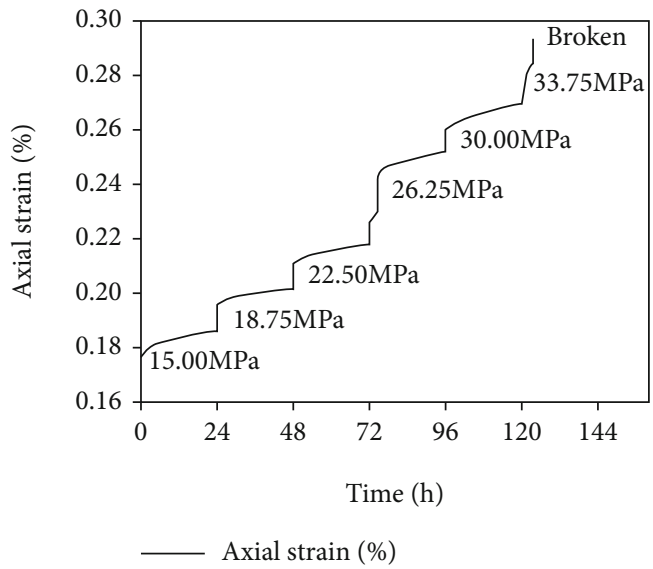

(d) Axial rheological curves of sample \#3

FIgURE 2: The step-loading uniaxial rheological test scheme and axial rheological curves.

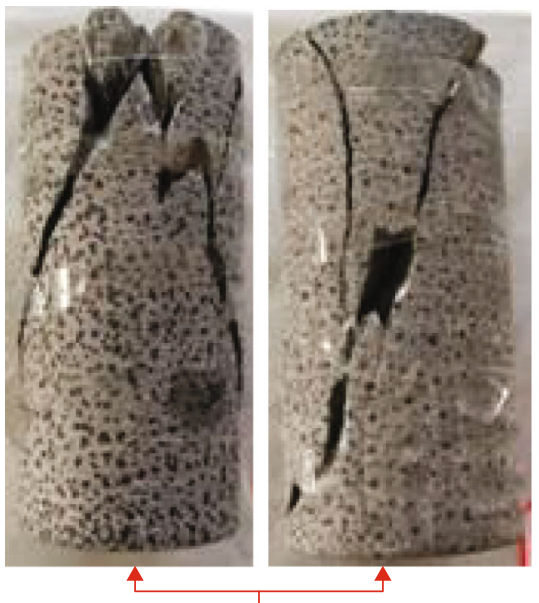

Under uniaxial compression

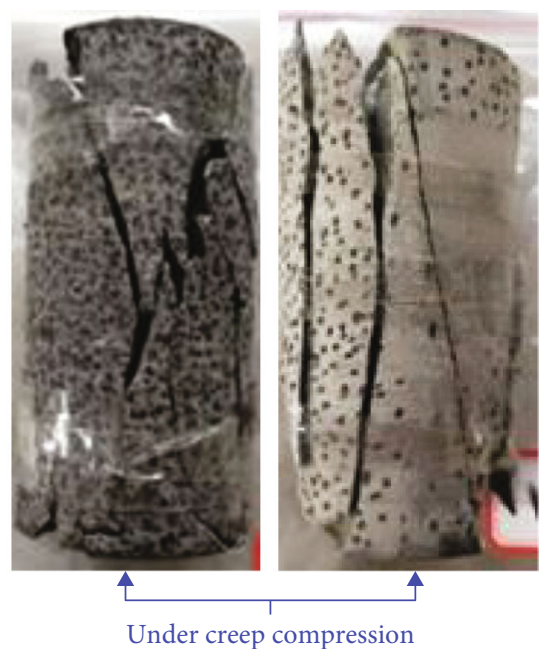

Under creep compression

FIGURE 3: Failure patterns of sandy mudstone samples under different loading conditions. 


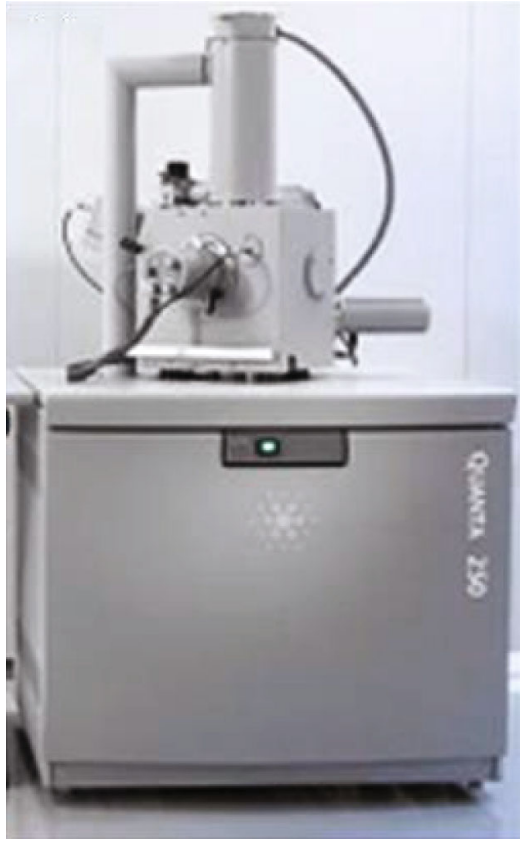

(a) Quanta ${ }^{\mathrm{TM}} 250$ SEM device

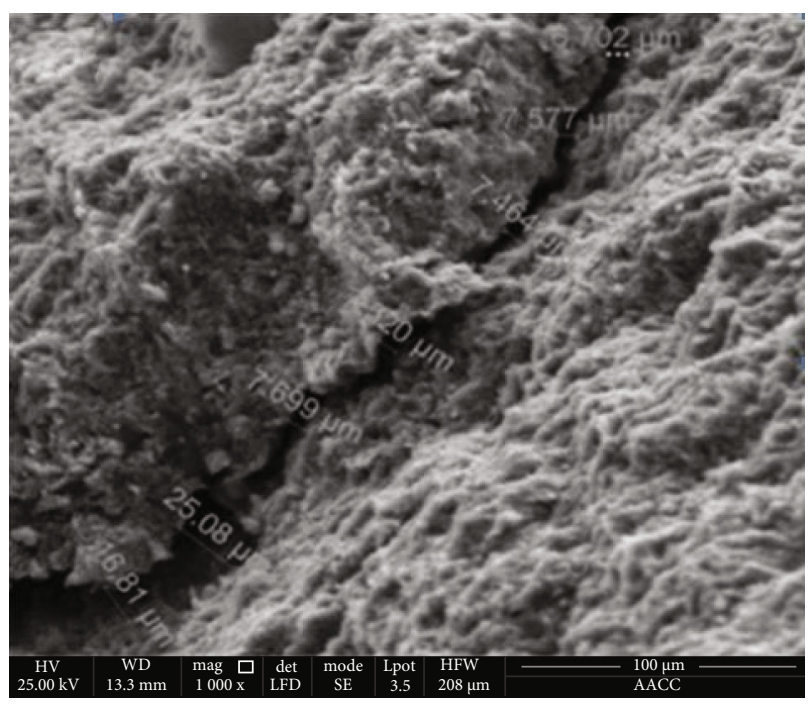

(b) The SEM image of the original sandy mudstone

Figure 4: The SEM device and a sample of SEM image.

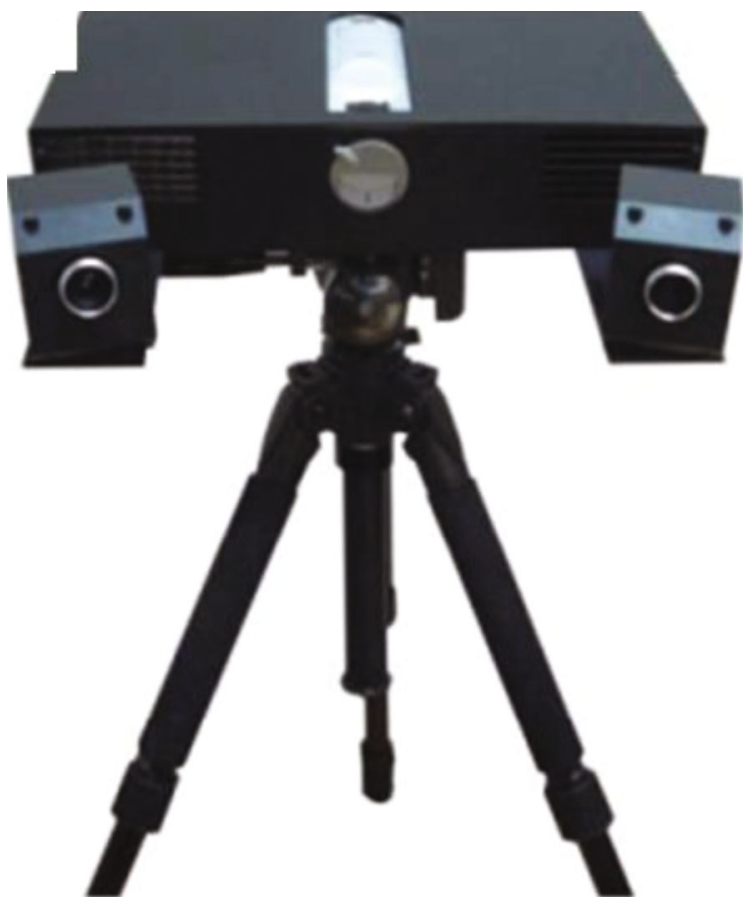

(a) The JR 3D scanning system

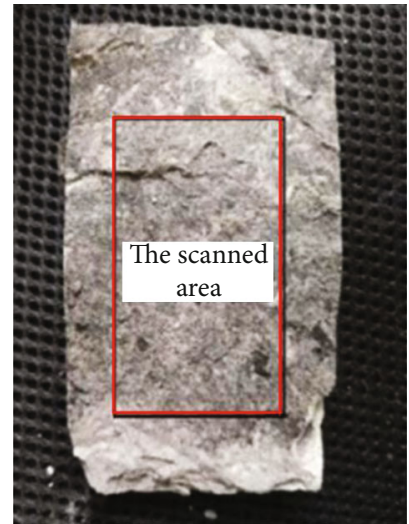

(b) The scanned specimens

FIGURE 5: The scanning equipment and the tested sample.

of sandy mudstone at the magnification of $\times 1000$ is displayed in Figure 4(b). It can be seen from the figure that, except for some primary pores and fissures inside the sandy mudstone sample, the other parts are relatively complete. The mineral particles are tightly cemented, and the coarse particles such as quartz are firmly wrapped by the clay mineral cement.
Furthermore, the JR 3D scanning system (Figure 5(a)) was used to characterize the topography of a typical sandy mudstone fracture surface after destruction. The system can complete single-sided scanning in less than 5 seconds with less than $0.015 \mathrm{~mm}$ accuracy and $0.04 \mathrm{~mm} / \mathrm{m}$ accuracy for fully automatic splicing. 


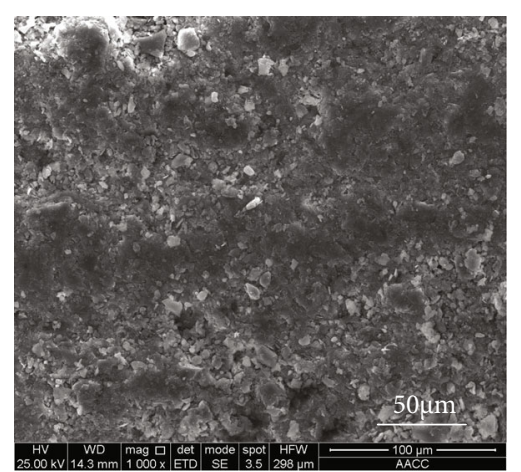

(a) Sample \#1 $(\times 2000)$

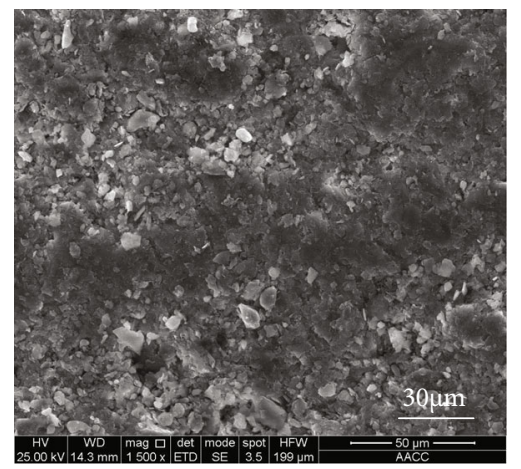

(c) Sample \#1 $(\times 3300)$

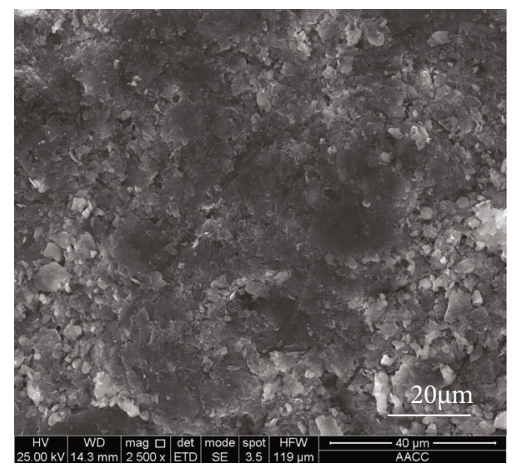

(e) Sample \#1 (×5000)

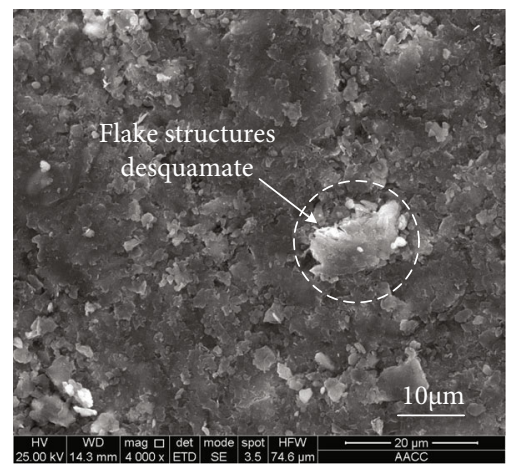

(g) Sample \#1 $(\times 10000)$

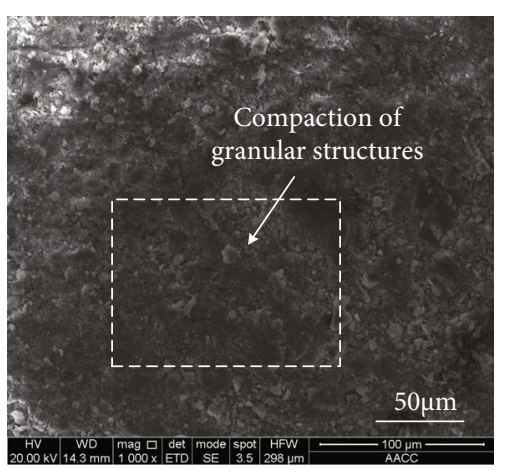

(b) Sample \#2 (×2000)

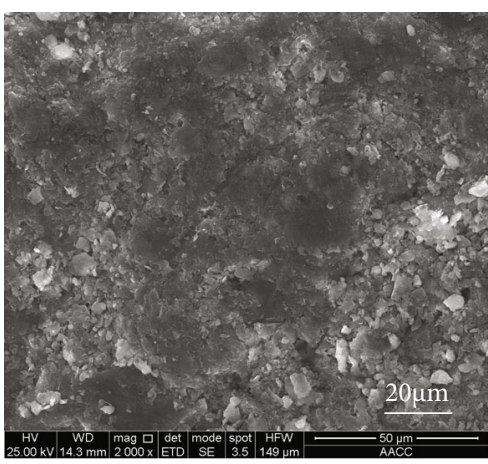

(d) Sample \#3 $(\times 5000)$

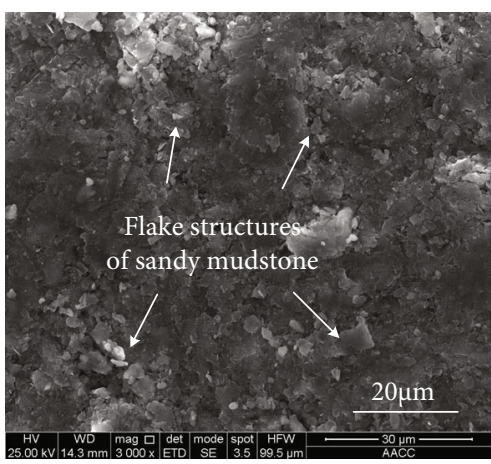

(f) Sample \#2 (×5000)

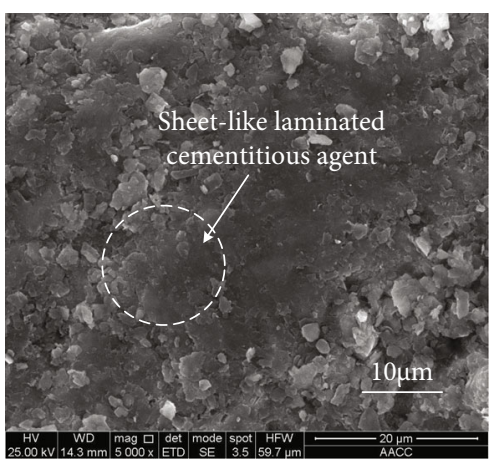

(h) Sample \#2 $(\times 10000)$

Figure 6: Microstructure of sandy mudstone specimens after uniaxial compression test. 


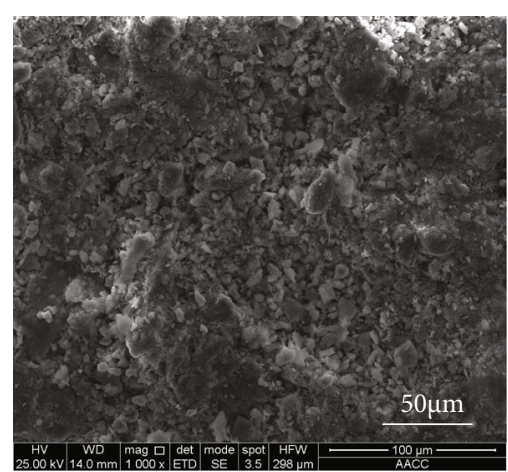

(a) Sample \#4 (×2000)

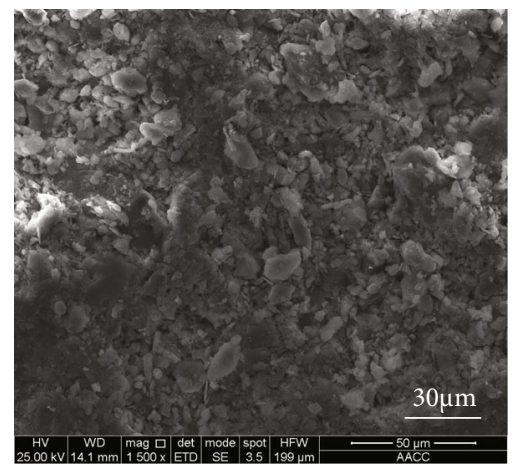

(c) Sample \#5 (×3300)

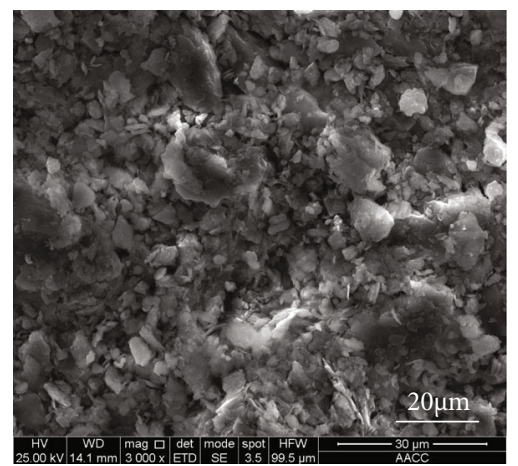

(e) Sample \#5 ( $\times 5000)$

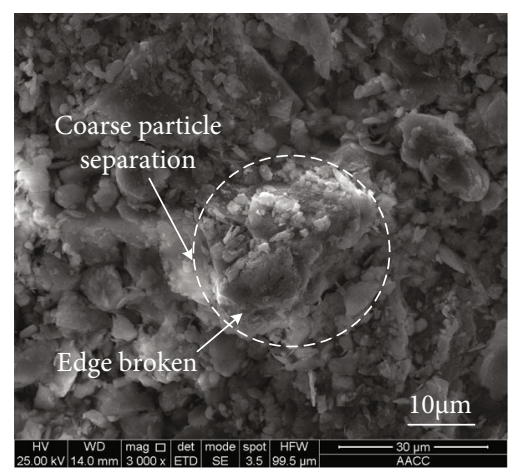

(g) Sample \#4 $(\times 10000)$

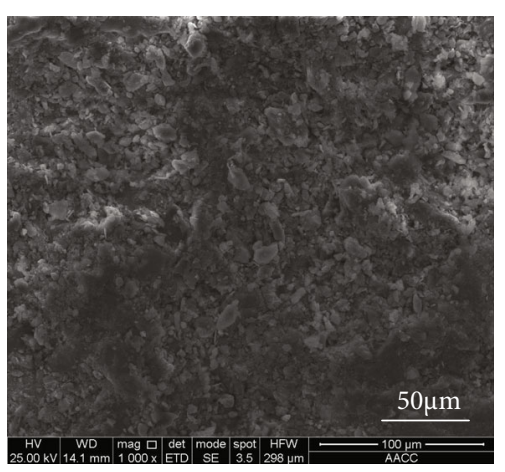

(b) Sample \#5 (×2000)

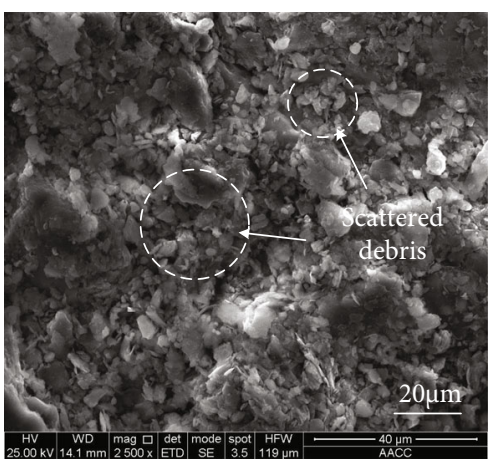

(d) Sample \#6 $(\times 5000)$

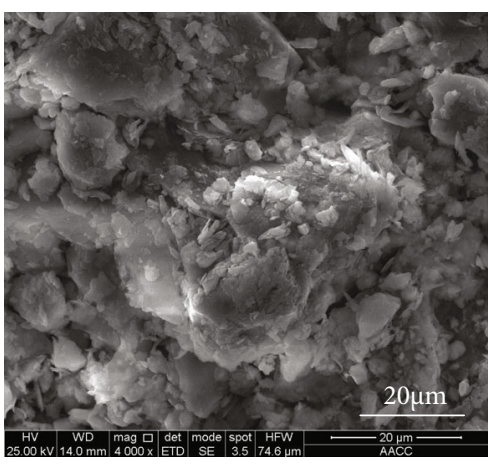

(f) Sample \#6 $(\times 5000)$

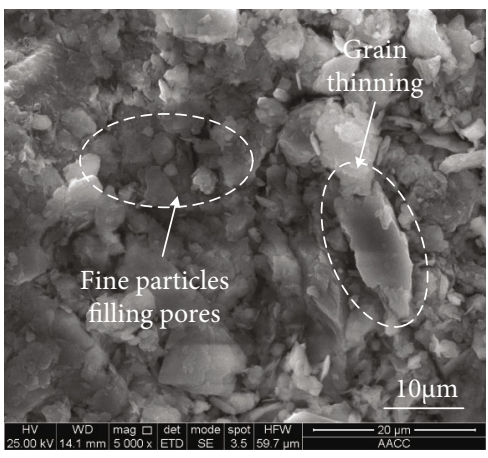

(h) Sample \#5 $(\times 10000)$

Figure 7: Microstructure of sandy mudstone specimens after uniaxial creep test. 


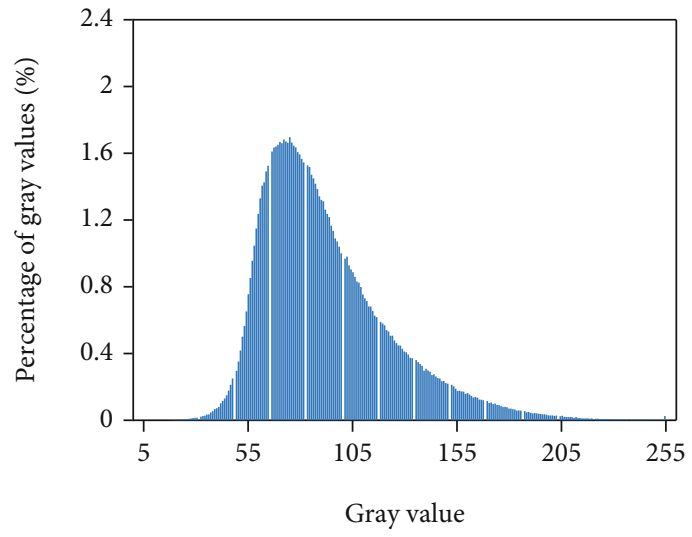

(a) Uniaxial compression sample ( $\times 1500$ magnification $)$

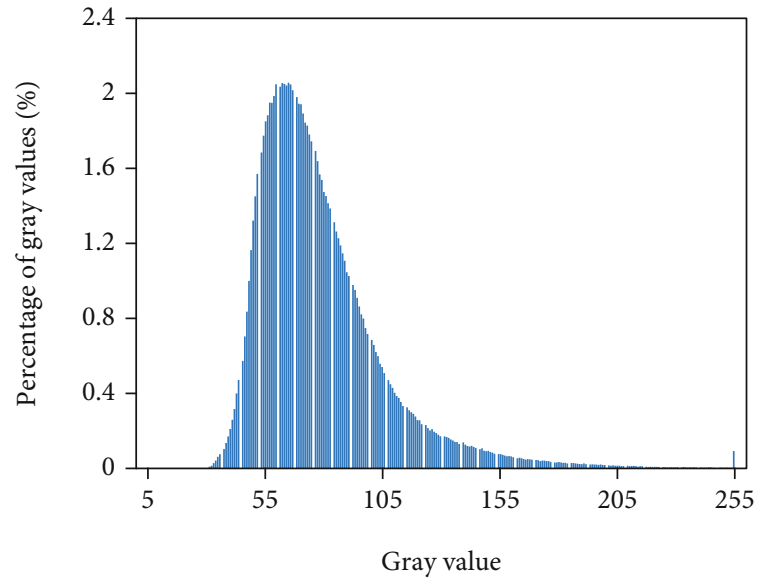

(b) Creep compression sample ( $\times 1500$ magnification)

FIGURE 8: The number of pixels versus different gray values (determining the gray threshold).

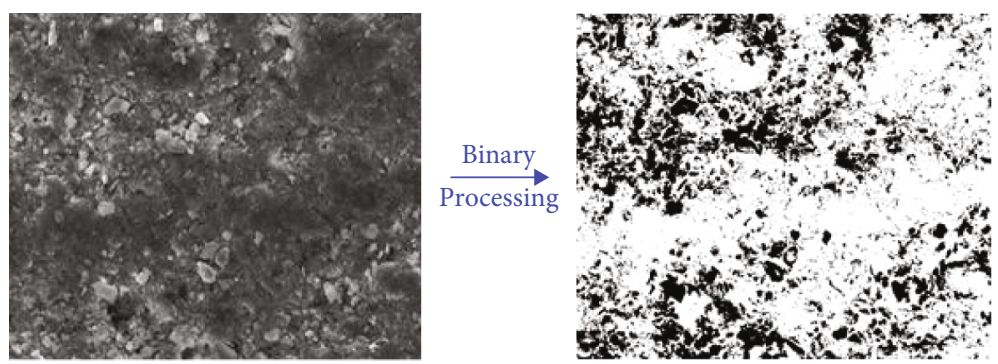

(a) Uniaxial compression sample at $\times 1500$ magnification
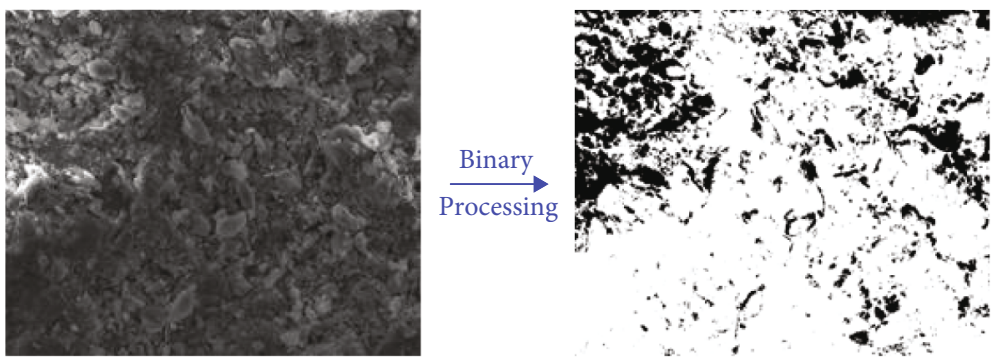

(b) Creep compression sample at $\times 1500$ magnification

Figure 9: Binary images of the microscopic structure of sandy mudstone specimens.

\section{Results and Discussion}

3.1. The Micromorphology of the Fracture Surface. The microstructure of the sandy mudstone specimens under creep action experienced a complex microscopic failure process from damage degradation to fracture and finally formed a corresponding microscopic fracture surface morphology. Hence, there is an excellent correlation between the microscopic morphology and the mechanical mechanism of microscopic damage.

The super-multiple microstructure of the fracture surface of the sandy mudstone specimens under a uniaxial compression test can be observed by SEM images, as shown in Figure 6. Compared with the microscopic topography of original sandy mudstone (Figure 4(b)), the flaky clay mineral particles in the specimens are relatively compacted after the uniaxial compression, indicating that the compressible phase, such as clay, mineral, kaolinite, and chlorite, in the specimens experienced a compaction process and resulted in an increase in the overall deformation stiffness of sandy mudstone.

It also can be found that the coarse particles composed of small pieces of fine clay mineral particles are closely stacked, interwoven, and crosslinked with each other and have characteristics aligned along a certain direction, as exhibited in Figure 6(f). The cementitious agents among the particles are relatively good, and few pores and fractures appear, making the fracture surface look flat and complete [20]. The flake structure of sandy mudstone clay minerals has some desquamation under uniaxial compression, as presented in Figure 6(h). Based on the morphology description above, the damage of sandy mudstone specimens under uniaxial compression is mainly due to microshear failure along the fracture surface [21]. 


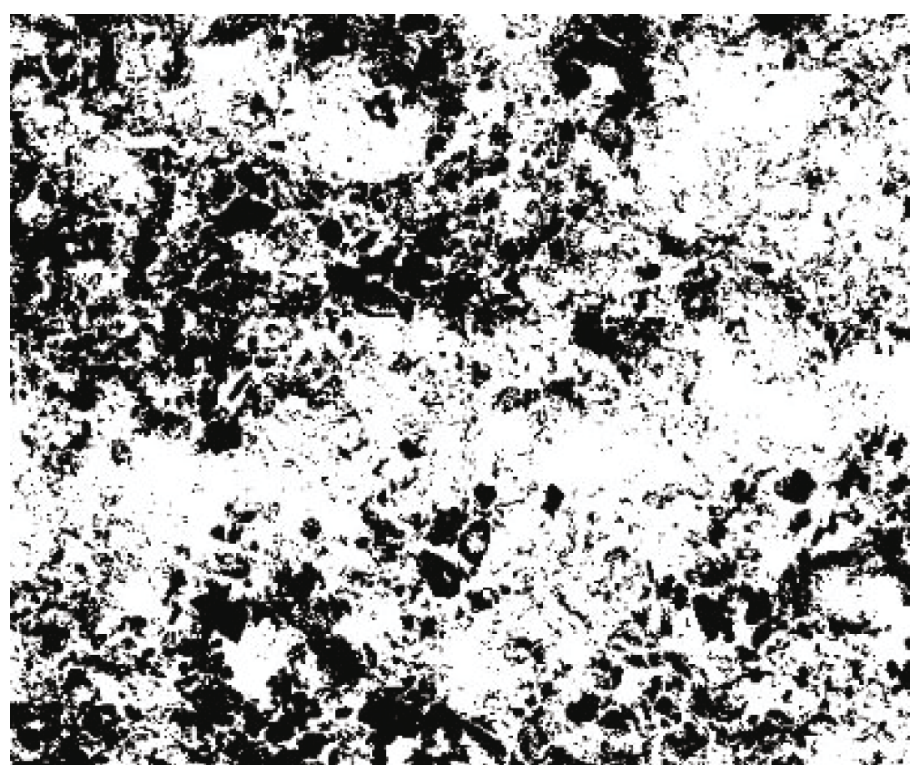

(a) 82867 boxes cover ( $r=2$ pixels)

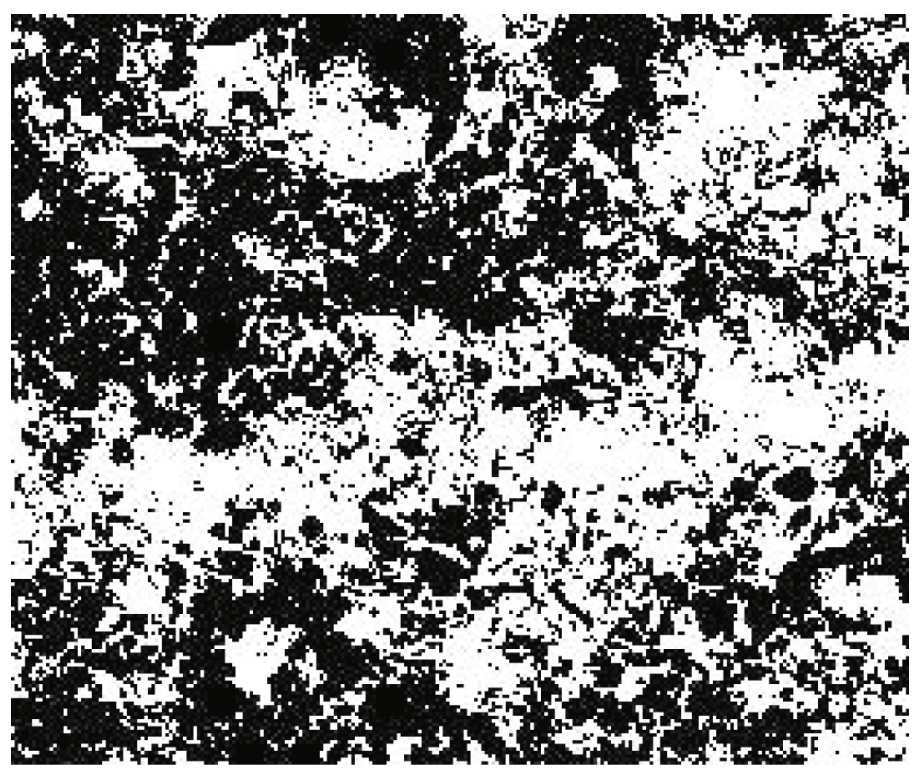

(b) 29587 boxes cover $(r=4$ pixel)

Figure 10: Continued. 


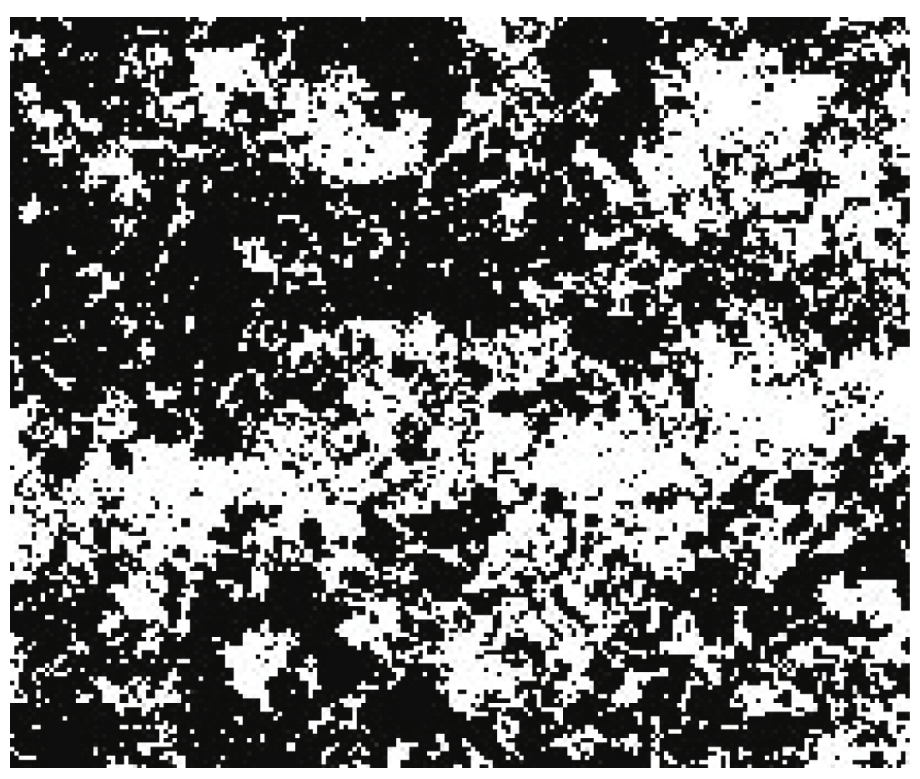

(c) 21236 boxes cover $(r=5$ pixel)

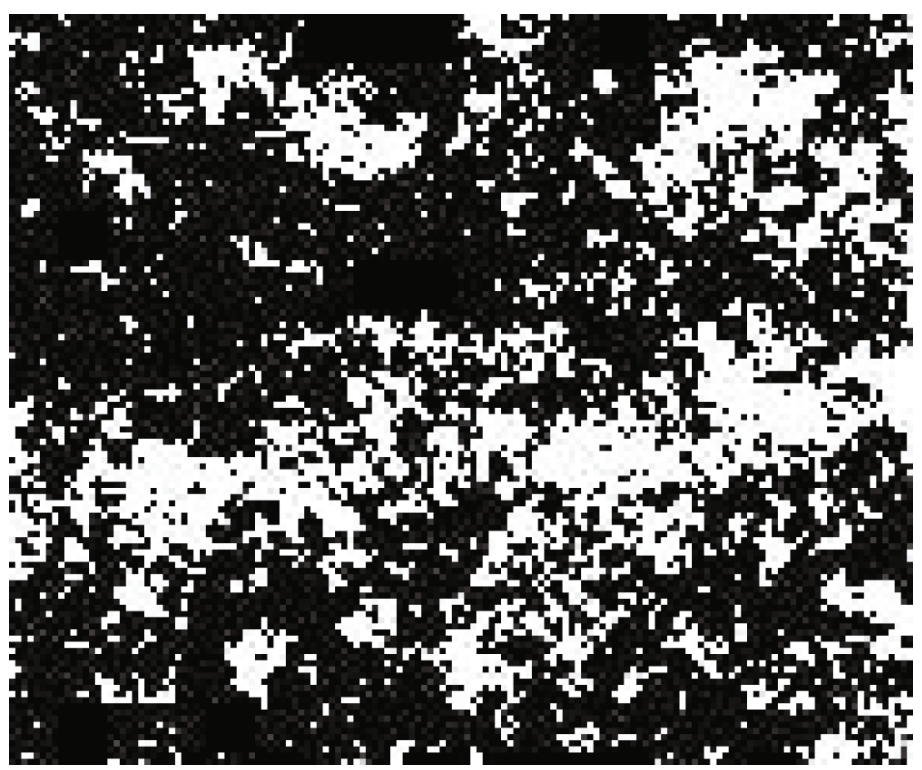

(d) 12702 boxes cover $(r=7$ pixel)

Figure 10: Continued. 


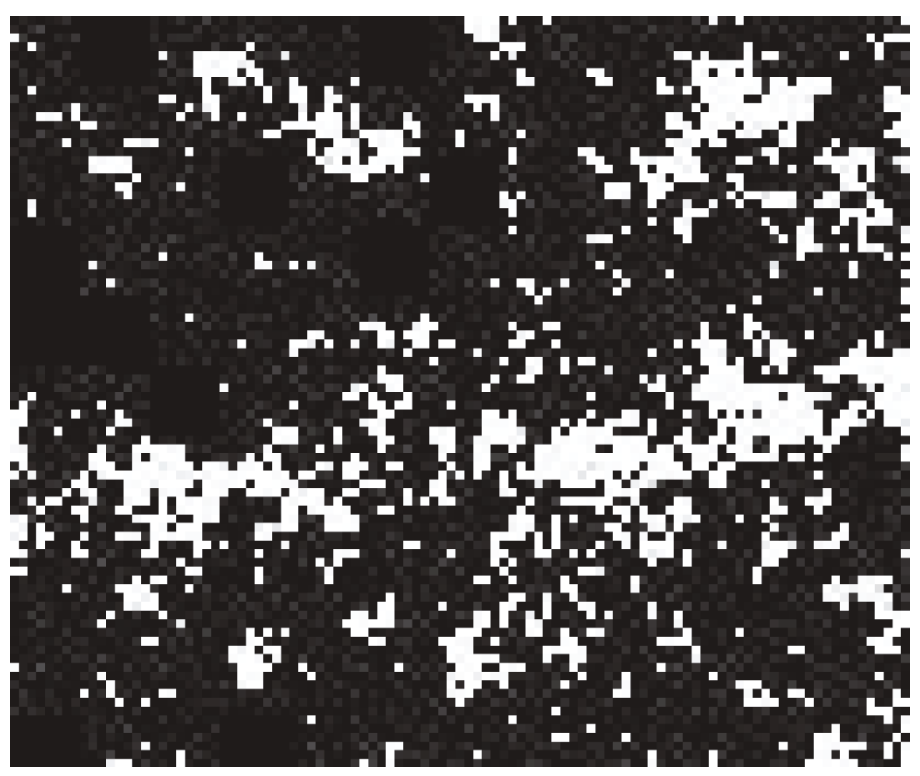

(e) 7206 boxes cover $(r=10$ pixel)

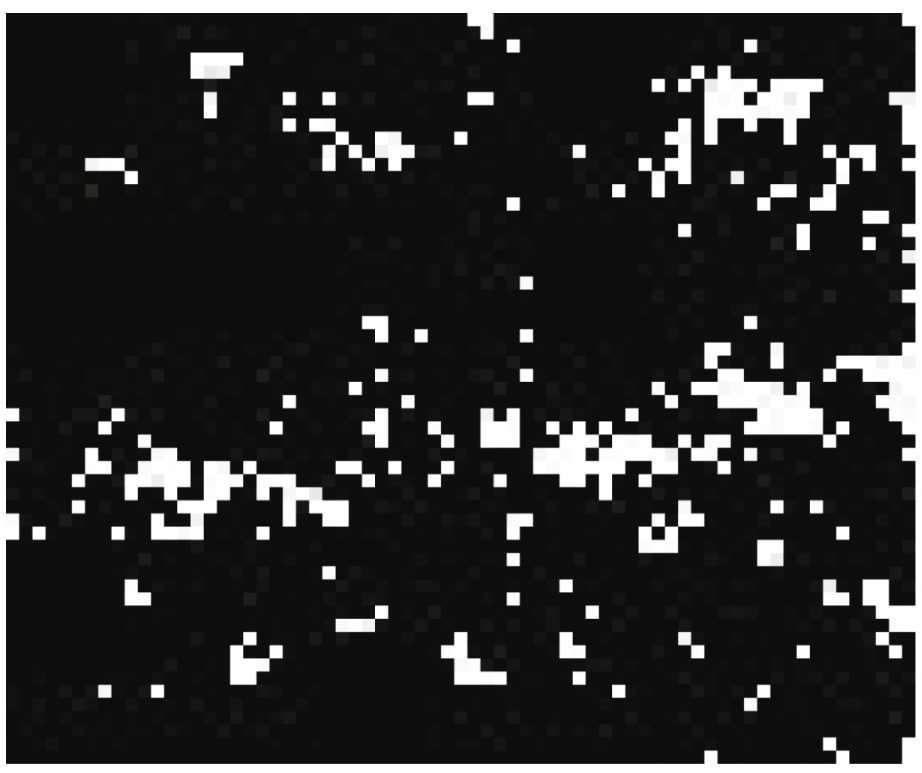

(f) 3551 boxes cover ( $r=15$ pixel)

Figure 10: Continued. 


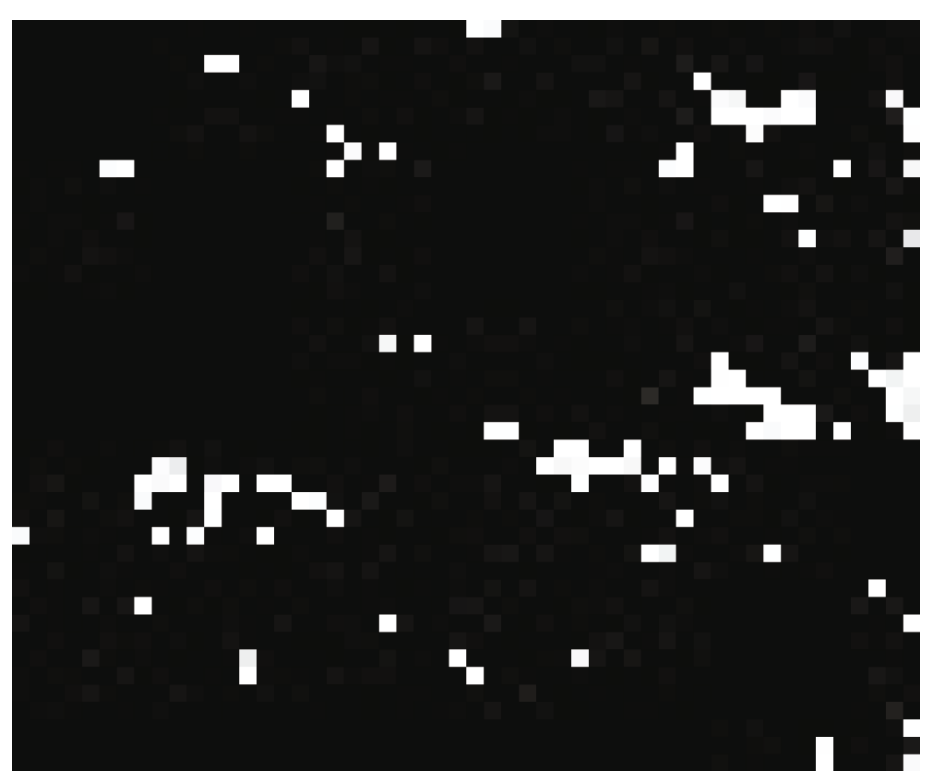

(g) 2121 boxes cover $(r=20$ pixel)

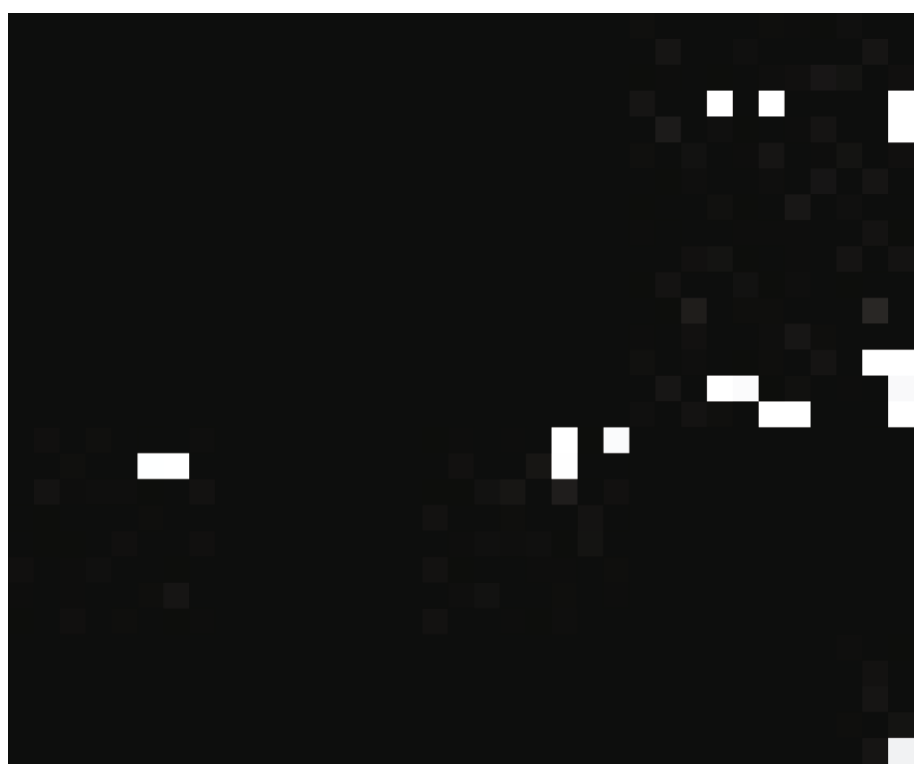

(h) 997 boxes cover $(r=30$ pixel)

FIgure 10: Continued. 


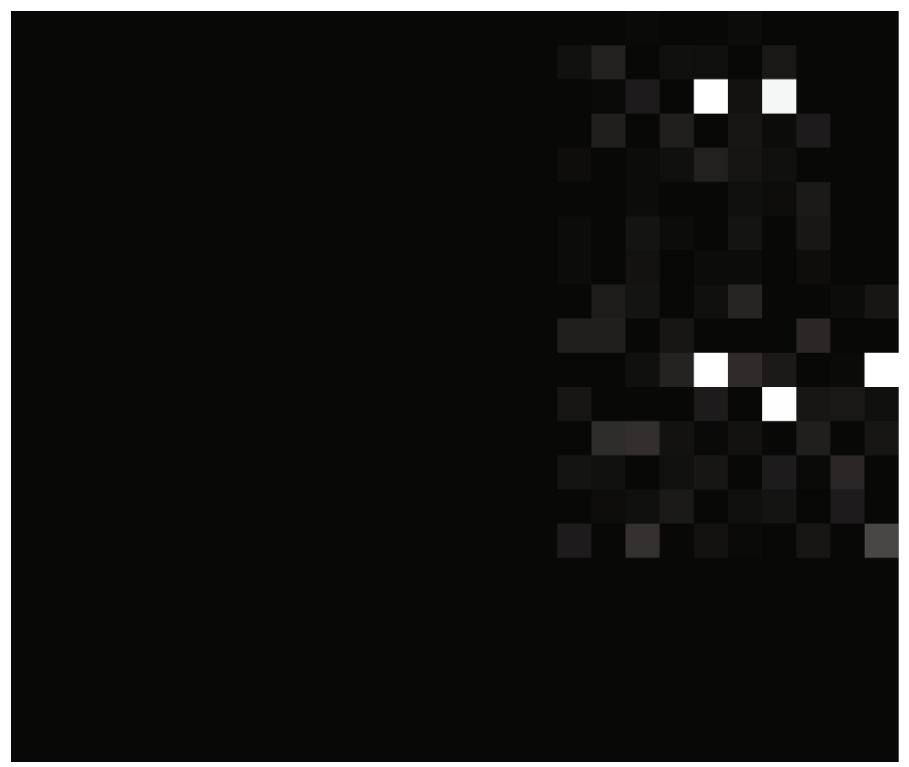

(i) 567 boxes cover $(r=40$ pixel)

FIgURE 10: The change process of the box size when the boxes cover the image in Figure 9.

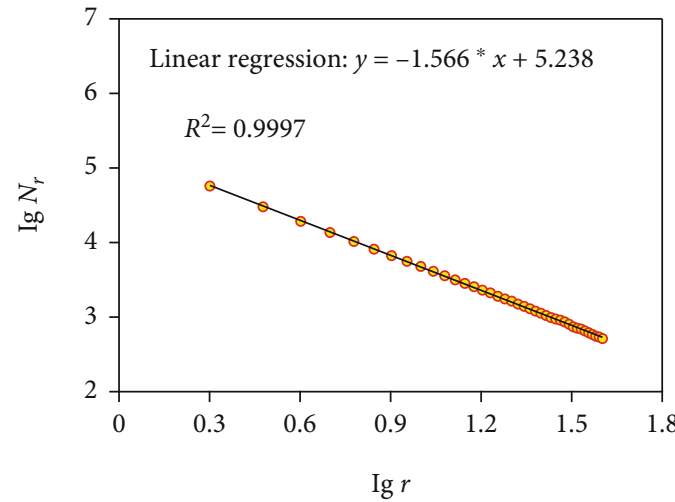

(a) Under uniaxial compression test

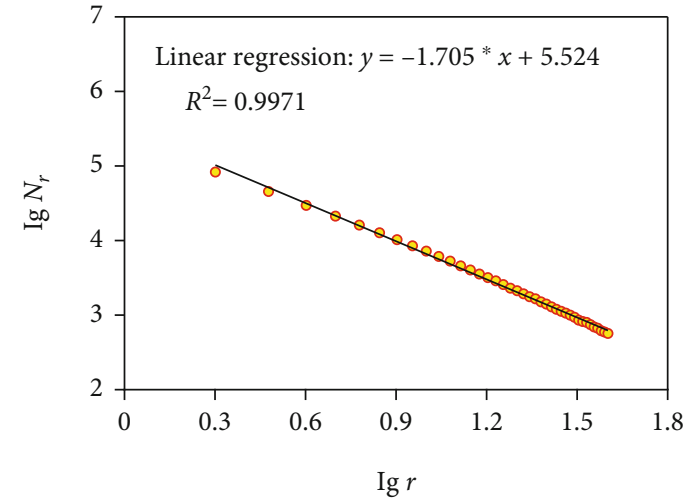

(b) Under uniaxial creep test

FIGURE 11: Box fractal dimensions of the microtopography of sandy mudstone specimens.

Figure 7 further characterizes the microscopic morphology of the fracture surface of the sandy mudstone specimens under the creep test. It is evident that at any magnification, the fracture surface micromorphology of the specimens after the creep test is more fractured and rougher. The creep stress path makes the damage to the internal integrity of the sandy mudstone specimens more serious, and the cementation of the particles is more broken.

The layered stack structure of flake clay mineral particles in sandy mudstone specimens has been severely damaged; the flaky particle structure is no longer stacked in an orderly manner, but fragmentation and peeling occur, and large flaky particles break into smaller ones, as presented in Figure 7(h). The intergranular cementation is destroyed, and micropores and microcracks are formed, which means that the sample no longer has a complete cemented microstructure. In this case, the particles are highly prone to shifting and the microstructure is relatively loose overall, with a layered peeling and chip-like structure. The coarse particle skeleton begins to peel off from the entire microstructure, and more new cracks are likely to occur at the boundary of the mineral particles, as shown in Figures $7(\mathrm{a})-7(\mathrm{c})$. In the magnified image (Figure 7(a)), small particles, which are produced from coarse particles after crushing and refining, begin to fill the fracture pores. Moreover, the irregularly shaped coarse particles are broken and refined, causing them to slip and rotate easily, resulting in continuously changing the entire microstructure's particle arrangement.

Previous studies reported that tensile failure and shear failure are the two main types of microscopic scale fracture in rock [22], which can be clearly observed from the SEM images of the fracture surfaces. The stripping of clay mineral cement is largely due to tensile and shearing action at the fracture surface. The essence of the sandy mudstone broken under a uniaxial creep test is that under the load, a series of fracture, refinement, slippage, and filling actions happen between the mineral particles inside the specimens. Under the long-term effect of stress history, the intergranular 
cementation of the sandy mudstone microstructure is continuously damaged and the distribution between particles is continuously adjusted to form a new bearing structure to withstand external loads.

Numerous studies have suggested that the heterogeneity of rocks, the long-term degradation of defects, and the cumulative effects of gradual accumulation eventually lead to creep damage in rocks [18]. The macroscopic deformation of rock under constant external load is essentially a nonlinear, statistically significant superposition of internal microscopic deformations. These microscopic deformations generally include lattice defect diffusion, coordinated deformation among particles, and initiation, expansion, and nucleation of microscopic fractures [23].

3.2. Fractal Characteristics of the Fracture Surface. To quantitatively describe the integrity and roughness of the rock fracture surface, this section presents the results of the digital image processing on the microscopic images of the fracture surface of sandy mudstone specimens obtained by SEM and then calculates the fractal dimension of the fractal box based on the fractal theory. The fractal dimension can be used to characterize the variation in the surface roughness of rocks, which is highly related to the complexity, nonuniformity, and regularity of the microstructure. The higher fractal dimension suggests a more irregular microscopic morphology and stronger nonuniformity of the specimens [24, 25].

The SEM images are all grayscale figures, which can be regarded as a matrix composed of pixel values. If there are $n$ image pixel points on a certain figure, the grayscale image is an $n$ element matrix with each element ranging from 0 to 255 [26]. However, although the black and white bitmap is also a matrix of $n$ elements, each element has only two colors, so the value ranges from 0 to 1 . For ease of processing and analysis, grayscale images can be converted into black and white bitmaps by selecting an appropriate grayscale threshold [27]. The grayscale threshold of the SEM microscopic images of sandy mudstone specimen fracture surfaces was determined using the maximum interclass variance (MIV) method [28]. As presented in the log-normal diagram of the gray value distribution (Figure 8), the threshold point can be determined to maximize the sum of the statistical variance of gray value data on the left and right sides.

To facilitate the processing of SEM images, the grayscale threshold was set by the abovementioned MIV method. As can be seen in Figure 9, two $\times 1500$ magnification SEM scan images were binarized, where the white is the relatively complete, flat surface and the black is the relatively broken, rugged part of the specimens.

The fractal dimension of the microscopic image of sandy mudstone specimen fracture surfaces was calculated using the box-counting dimension (BCD) method [26], which is defined as follows. Let $B \in R^{n}, B \neq \varnothing, \forall r>0, N_{r}(B)$ is defined as the minimum number of $n$-dimensional cubes required to cover set $B$, where $r$ is the length of the cube side. If $r \longrightarrow 0$, the fractal box dimension $(d)$ of set $B$ would satisfy equation (1) as follows:

$$
N_{r}(B) \propto \frac{1}{r^{d}}
$$

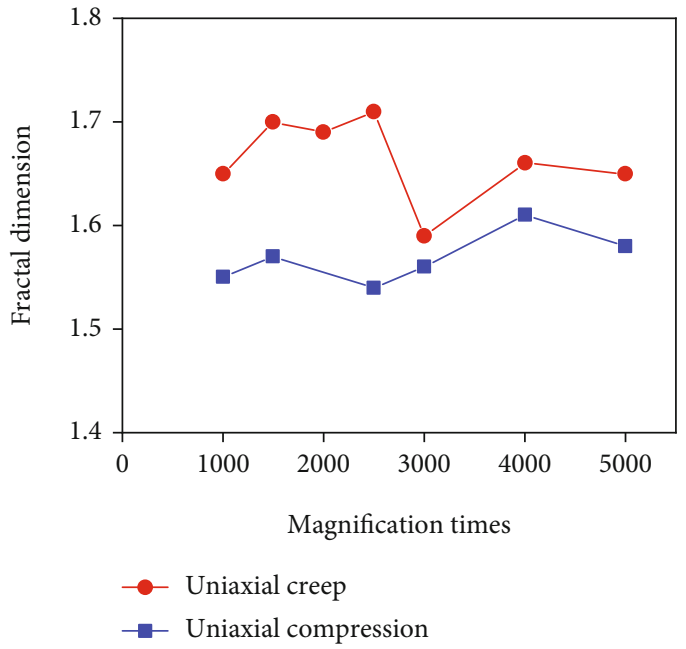

FIgURE 12: Box fractal dimensions under different magnification times.

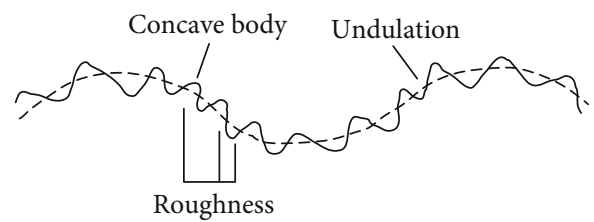

FIgURE 13: Micromesoscopic asperity definition of a rock fracture surface [30].

There is a unique positive number $a$ such that

$$
\lim _{r \longrightarrow 0} \frac{N_{r}(B)}{1 / r^{d}}=a
$$

Take the logarithm of both sides of equation (2), and then, take the absolute value to ensure that the $d$ value is nonnegative

$$
d=\left|\lim _{r \longrightarrow 0} \frac{1 g a-1 g N_{r}(B)}{1 g r}\right|=\left|\lim _{r \longrightarrow 0} \frac{1 g N_{r}(B)}{1 g r}\right|
$$

Figure 10 illustrates the process of calculating the fractal dimension of sandy mudstone fracture surface micromorphology. The black portion of Figure 10(a) is covered with square black pixel blocks of different sizes, as exhibited in Figures $10(\mathrm{a})-10(\mathrm{~g})$, with the corresponding square block length, $r$, continuously increasing and the required number continuously decreasing.

The SEM-binarized image of the sandy mudstone specimen fracture surface under the creep test presented in Figure 9(b) was treated similarly. The number of blocks required to cover the black portion under the square block size value, $r$, is $N r(B)$, and the scatter plots of $\left(1 g r_{i}, 1 g N_{r i}(B)\right)$ are shown in Figure 11. Through linearly fitting the scatter points, the goodness of fitting correlation coefficient $\left(R^{2}\right)$ was found to be larger than 0.99 , indicating that the micromorphology 


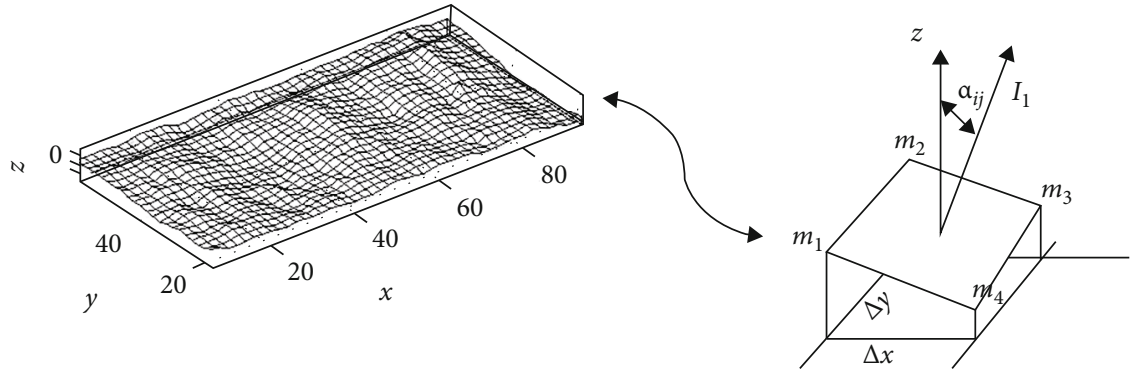

Three-dimensional surface

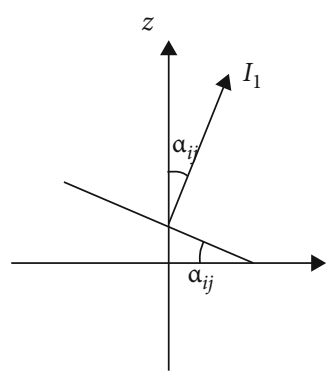

Two-dimensional surface

FIGURE 14: Inclination angle of elementary surface.

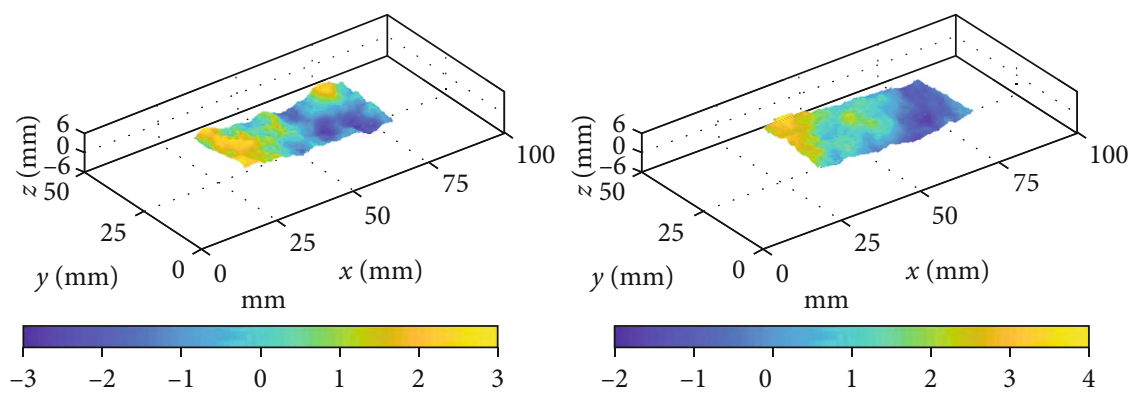

(a) Sample 1 and sample 2 under uniaxial compression
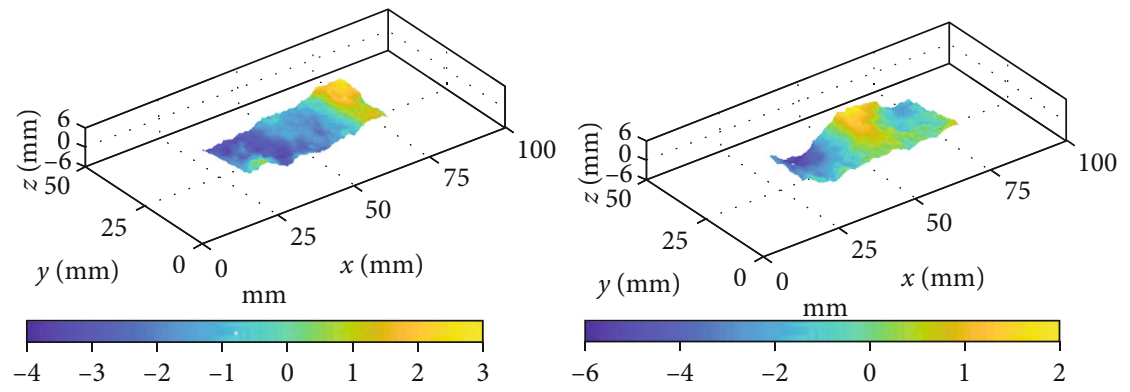

(b) Sample 3 and sample 4 under creep compression

FigURE 15: 3D reconstruction of sandy mudstone specimens' typical fracture surface.

of sandy mudstone fracture surface has self-similarity from a statistical point of view.

The results of the two samples show that the fractal dimension of the specimen under the uniaxial creep test is 1.70, while under the uniaxial compression test, it is only 1.57. A similar proceeding process and fractal analysis were performed on the other SEM images, and the fractal dimension of SEM images at different magnifications is shown in Figure 12.

At any magnification, the fractal dimension of the sandy mudstone specimen creep fracture is larger than that after the uniaxial compression test, proving the increased irregularity and larger degree of roughness fluctuation for the uniaxial creeping sandy mudstone specimens on the microscopic scale. Compared with the surface destroyed under uniaxial compression, the uniaxial creep fracture surface has large microroughness, large specific surface area, poor regularity, and poor uniformity, hence having a stronger space filling ability.
3.3. Analysis of the Mesoscopic Asperities of the Fracture Surface. Fractography has three different scale descriptions of a fracture surface, including shape, undulation, and roughness [29]. At the macrolevel, shape and undulation are usually used to describe the geometric characteristics of a fracture surface, while on the microscopic level, roughness is applied to characterize the geometry of the fracture surface. In fact, the microroughness refers to the unevenness degree of a concave body attached on a smaller scale to the macroscopic undulating surface $[29,30]$, as shown in Figure 13.

Previous studies reported many methods for qualitatively and quantitatively evaluating the microscopic roughness of rock fracture surfaces [31]. Barton and Barton and Choubey $[32,33]$ proposed to evaluate the roughness of the fracture surface by visual inspection, comparison, and reference to 10 standard JRC curves. Based on this theory, many researchers further focused on exploring and developing effective statistical methods and fractal methods to accurately characterize the roughness of the fracture surface $[29,34]$. 

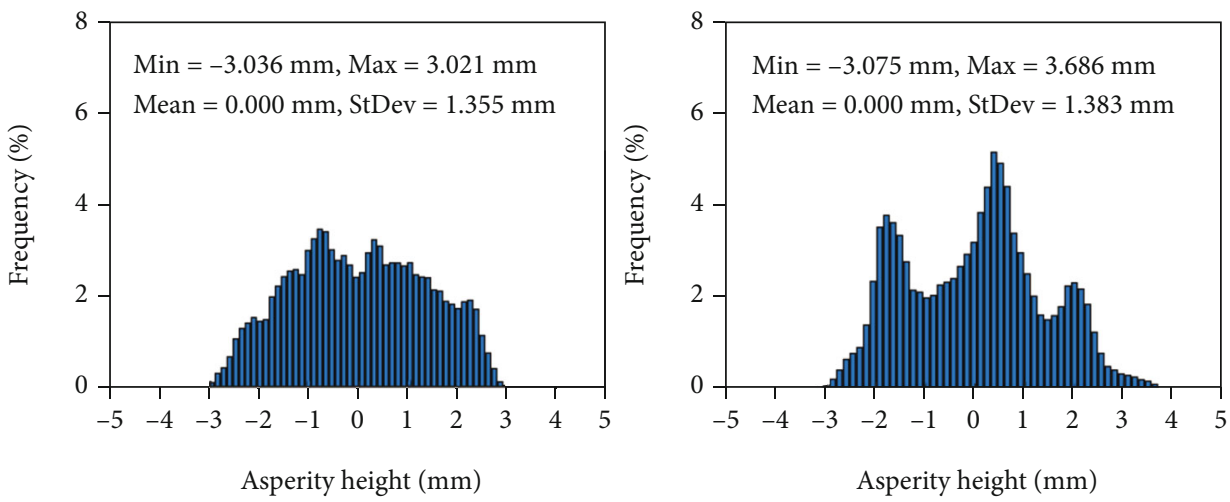

(a) Sample 1 and sample 2 under uniaxial compression
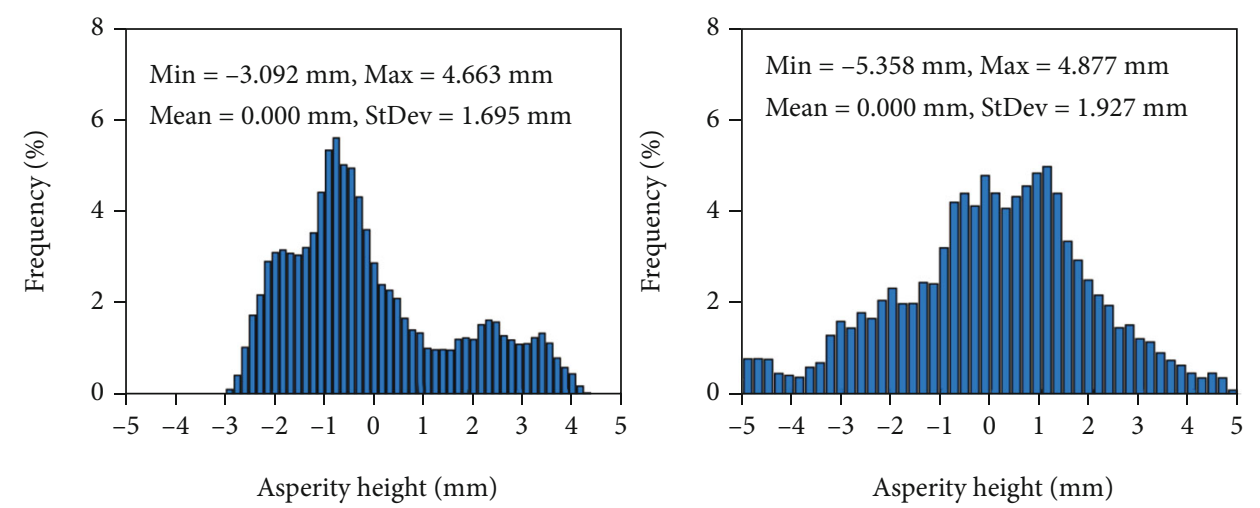

(b) Sample 3 and sample 4 under creep compression

FIGURE 16: Mesoscopic asperity height of sandy mudstone specimens' fracture surface.

The method of mesoscopic roughness of the creepinduced fracture surface of sandy mudstone used in this study is based on Belem et al.'s [35] microscopic morphology statistical method. As shown in Figure 14(a), the scanning point cloud data of the three-dimensional fracture surface was discretized and meshed into a series of mesoscopic planes. For any mesoscopic plane, the local inclination angle $\left(\alpha_{i j}\right)$ is defined as the angle between it and the horizontal plane, which is also the angle between the normal vector, $n$, and the plane $z$-axis, as shown in Figure 14(b). Perform statistics on $\alpha_{i j}$ and the height of each mesoscopic plane corner to obtain maxima, minima, means, and standard deviations.

The typical fracture surfaces of the sandy mudstone specimens after uniaxial compression and creep tests were scanned using the JR 3D scanning system to obtain point cloud data of the fracture surface. Images from the 3D reconstruction using MATLAB are shown in Figure 15.

The 3D-scanned point cloud data was then discretized into a grid to calculate the mesorough height of each grid point. Figure 16 shows the calculated results of the surface mesorough height distribution for the four 3D scanning specimens. It is obvious that the standard value of the rough surface height of the fracture surface from the creep test is larger than that from the uniaxial compression test, indicating that the degree of macroscopic fluctuation of the creep fracture surface is relatively high and forming the fracture surface overcomes more surface energy. During the creep process of sandy mudstone, the crack propagation path is more complicated and tortuous.

The statistics of the sandy mudstone specimen fracture surface mesoscopic plane local inclination angle reflects the mesoroughness characteristics of the fracture surface [36]. Figure 17 shows the measured results of the mesoscopic slope angle of sandy mudstone specimen fracture surfaces. Both the mean value and the standard deviation of the specimens under the uniaxial compression test are smaller than those under the uniaxial creep test, indicating that the degree of change of the mesoplane slope in space is also greater and the corresponding fracture surface is rougher.

The sandy mudstone specimens accumulate a certain amount of energy during the initial creep loading process. Due to the nonuniformity of the rock material, under the constant load, the energy accumulated in the sandy mudstone specimens begins to be released to the stress concentration zone at the tip of the microcrack, which makes the expansion path of the crack more complicated. However, uniaxial compression has a high loading rate compared to creep, the accumulated energy is not released, and the crack propagation path is relatively simple, resulting in a relatively small macroscopic undulation of the fracture surface.

It can be speculated that in the process of gradually damaging the sandy mudstone specimens under creep, more secondary cracks around the fracture surface would appear and the vertical fracture surface would extend deeper. The final 

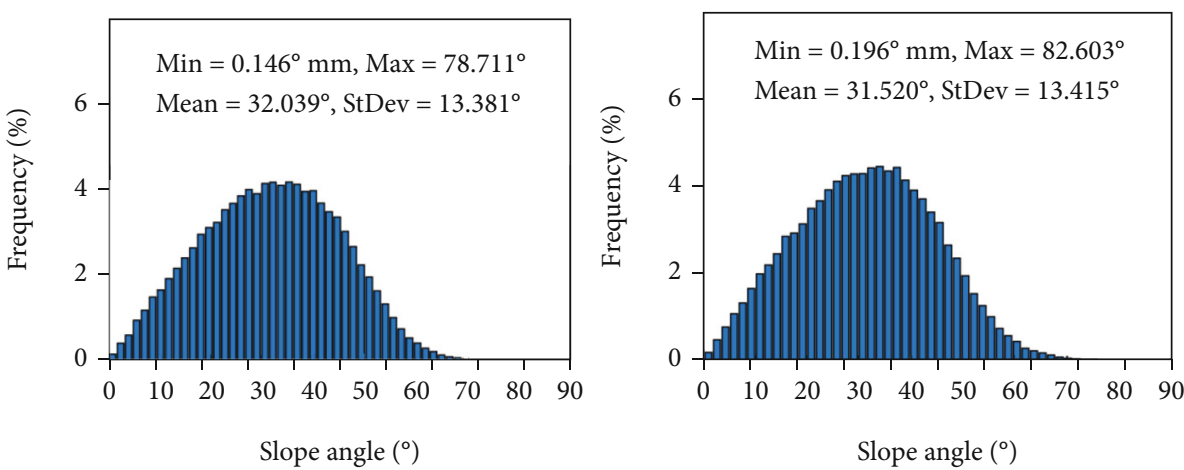

(a) Sample 1 and sample 2 under uniaxial compression

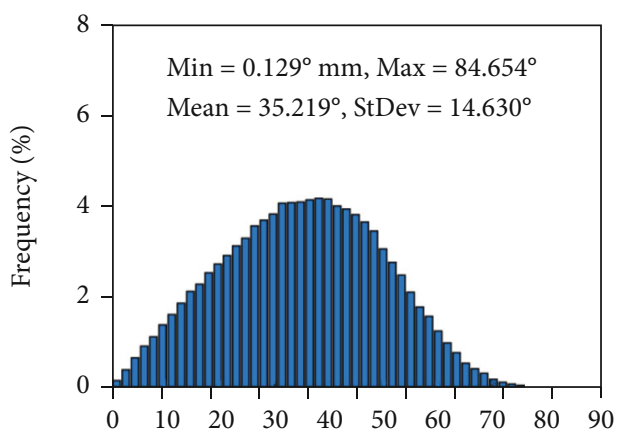

Slope angle $\left({ }^{\circ}\right)$

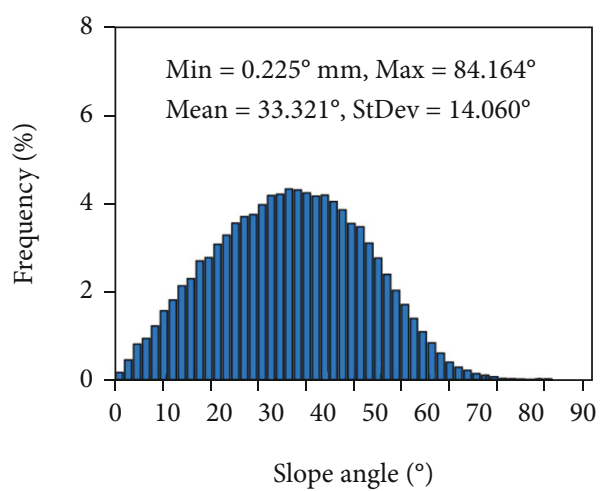

(b) Sample 3 and sample 4 under creep compression

Figure 17: Mesoscopic slope angle of sandy mudstone specimen fracture surfaces.

resulting fracture surface undulation would be relatively high. However, under uniaxial compression conditions, fewer cracks were around the fracture surface of the specimens. Because there is a certain loading rate, there is insufficient time to let the secondary crack extend around the fracture surface and the undulation will be relatively low.

\subsection{Relationship between Mesoscopic Roughness and} Mesoscopic Shear Dilation. Based on the relevant research findings of direct shearing of rock joints $[29,37]$, the macroscopic deformation of sandy mudstone specimens during the creep process, especially in volume expansion, is largely influenced by the dilatancy effect of the fracture surface. Due to the uneven distribution of microscopic defects, such as sandy mudstone components and internal pores or fractures, it is generally difficult to accurately and quantitatively measure this mesoscopic dilatancy effect.

Only the two-dimensional case is considered in this section. The effect of the fracture surface microscopic roughness characteristic on the mesoscopic shear impact of sandy mudstone specimens was studied based on the calculated mesoscopic asperity height and slope angle. Moreover, the fracture surface geometry of complex sandy mudstone specimens was discretized, simplified, and abstracted into several straight microsections connected end to end along the surface to construct a microelement mode. Finally, the microscopic dilatancy angle under uniaxial compression and uniaxial multistage creep conditions of the sandy mudstone was estimated. The mesoscopic tangential climbing and

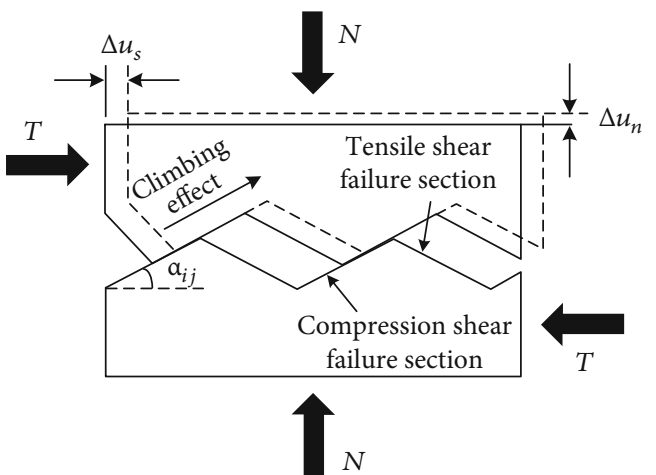

FIGURE 18: Mesoscopic shear dilation of a sandy mudstone fracture surface.

dilatancy effects of the sandy mudstone specimen fracture surfaces were mesomechanical mechanisms for the macroscopic dilatancy of the failure. The larger the mesoroughness was, the higher the sandy mudstone's mesoclimbing height was, and the corresponding macroscopic dilatancy effect was more obvious.

The schematic view of the microscopic dilatancy effect of the fracture surface of a sandy mudstone specimen is presented as Figure 18. $\Delta u_{n}$ and $\Delta u_{s}$ are the normal dilatancy deformation and the corresponding tangential shear deformation of the fracture surface of the sandy mudstone, respectively. The specimens had both a tensile-shear failure microsection and a compression-shear failure microsection 
at the fracture surface during the loading process. As can be seen in Figure 16, due to the mesoclimbing effect, the entire fracture surface of the sandy mudstone specimens causes dilatation and expansion. When the shear stress of the compression-shear microsection is larger than the residual shear strength of the microsection, the corresponding microsection was further influenced by the normal dilatancy effect on a smaller scale. The abovementioned deformation effects together constitute the cause of the dilatancy expansion of the fracture surface. As can be seen from the above analysis, the macroscopic dilatancy deformation of the fracture surface of the sandy mudstone mainly depends on the microscopic inclination angle roughness $\left(\alpha_{i j}\right)$ and the mesoscopic shear displacement $\left(\Delta u_{s}\right)$ of each fracture microsection.

For the microbody of the sandy mudstone specimen fracture surface shown in Figure 16, the dilatancy angle, $\psi$, satisfied the following equation:

$$
\tan (\psi)=\frac{\Delta u_{n}}{\Delta u_{s}} \approx \tan \left(\alpha_{i j}\right) .
$$

In Section 3.3, from the point of view of statistics, the microbody of the fracture surface of sandy mudstone under uniaxial compression has a microscopic dilatancy angle of about $31.5^{\circ}$, while that under uniaxial creep conditions is about $35.2^{\circ}$. Assuming the tangential shear deformation, $\Delta$ $u_{s}$, is the same, the normal dilatancy deformation, $\Delta u_{n}$, of the sandy mudstone specimen fracture surfaces under uniaxial creep will be 1.15 times larger than that of the uniaxial compression condition.

The above-calculated results suggest that the larger the local inclination angle of the mesoplane of the sandy mudstone specimen fracture surface, the more obvious the dilatancy effect will be. The mesoroughness and mesolocal inclination angle of the sandy mudstone specimens after creep failure were larger than those of the uniaxial compression failure, indicating that the dilatancy effect will be more pronounced in the creep process. This also explains the mechanism by which the sandy mudstone experienced large deformation under constant load on the mesoscopic level.

\section{Conclusions}

This study investigated the microstructure of the fracture surface of sandy mudstone specimens under uniaxial creep conditions compared with uniaxial compression tests and then showed the micromesoscopic shear dilation mechanism based on asperity and fractal theory. The main conclusions are as follows:

(1) The micromorphology of the sandy mudstone specimen fracture surfaces is more broken, looser, and less uniform after creep failure than that after uniaxial compression failure, suggesting that the creep effect aggravates damage inside the samples. The SEM images show that the creep-induced coarse-grained fractures of the sandy mudstone were refined into smaller particles, and then, the debris slipped to fill the tiny pores
(2) The fractal dimensions calculated from SEM microscopic images of the fracture surface of the sandy mudstone specimens under uniaxial creep condition were larger than those under uniaxial compression test in all seven magnification. This result indicated that the creep effect causes damage irregularity in the sandy mudstone specimens on the microscopic scale, both in the degree of particle fragmentation and the degree of rough fluctuation. Creep-induced damage will develop deep to the fracture surface

(3) $3 \mathrm{D}$ scanning results show that the creep-induced macroscopic undulation and the standard deviation of the mesorough height of the fracture surface are about $8.0-10.0 \mathrm{~mm}$ and $1.7-1.9 \mathrm{~mm}$, respectively. However, the corresponding parameters after uniaxial compression failure are only around $6.0-7.0 \mathrm{~mm}$ and $1.3-1.4 \mathrm{~mm}$, suggesting that the roughness of the former is larger than the latter on the mesoscopic level

(4) By establishing the dilation model, the mean value of the mesoplane local inclination angle of the mesofracture surface of the sandy mudstone specimens under the two stress conditions of uniaxial creep and uniaxial compression was evaluated, about $35.2^{\circ}$ and $31.5^{\circ}$, respectively. In the case where the tangential shear deformation is the same, the normal mesoscopic dilatancy deformation amount induced by creep will be 1.15 times larger than that caused by uniaxial compression, indicating that the dilatancy effect will be more pronounced in the creep process

\section{Data Availability}

The data used to support the findings of this study are included within the article.

\section{Conflicts of Interest}

The authors declare that there are no conflicts of interest regarding the publication of this paper.

\section{Acknowledgments}

This work is supported by the joint Ph.D. program of "double first rate" construction disciplines of CUMT.

\section{References}

[1] A. Alberto and S. Valente, "Asymptotic fields at the tip of a cohesive frictional crack growing at the bi- material interface between a dam and the foundation rock," Engineering Fracture Mechanics, vol. 108, pp. 152-161, 2013.

[2] S. Li, Z. Wang, Y. Ping, Y. Zhou, and L. Zhang, "Discrete element analysis of hydro-mechanical behavior of a pilot underground crude oil storage facility in granite in China," Tunnelling and Underground Space Technology, vol. 40, pp. 75-84, 2014.

[3] J. Wang, P. Q. Qiu, J. G. Ning, L. Zhuang, and S. Yang, “A numerical study of the mining-induced energy redistribution 
in a coal seam adjacent to an extracted coal panel during longwall face mining: a case study," Energy Science \& Engineering., vol. 8, no. 3, pp. 817-835, 2020.

[4] S. Q. Yang, W. L. Tian, and P. Ranjith, "Experimental investigation on deformation failure characteristics of crystalline marble under triaxial cyclic loading," Rock Mechanics and Rock Engineering, vol. 50, no. 11, pp. 2871-2889, 2017.

[5] Y. Zhang, Y. Jiang, D. Asahina, and C. Wang, "Experimental and numerical investigation on shear failure behavior of rock-like samples containing multiple non-persistent joints," Rock Mechanics and Rock Engineering, vol. 53, no. 10, pp. 4717-4744, 2020.

[6] J. W. Park, J. Rutqvist, D. Ryu, E.-S. Park, and J.-H. Synn, "Coupled thermal-hydrological-mechanical behavior of rock mass surrounding a high-temperature thermal energy storage cavern at shallow depth," International Journal of Rock Mechanics and Mining Sciences, vol. 83, pp. 149-161, 2016.

[7] X. S. Liu, D. Y. Fan, Y. L. Tan et al., "Failure evolution and instability mechanism of surrounding rock for close-distance Parallel chambers with super-large section in deep coal mines," International Journal of Geomechanics, vol. 21, no. 5, p. 4021049, 2021.

[8] X. Li, C. Qi, and Z. Shao, “A microcrack growth-based constitutive model for evaluating transient shear properties during brittle creep of rocks," Engineering Fracture Mechanics, vol. 194, pp. 9-23, 2018.

[9] K. Miura, Y. Okui, and H. Horii, "Micromechanics-based prediction of creep failure of hard rock for long-term safety of high-level radioactive waste disposal system," Mechanics of Materials, vol. 35, no. 3-6, pp. 587-601, 2003.

[10] L. Yu, Z. Zhang, J. Wu, R. Liu, H. Qin, and P. Fan, "Experimental study on the dynamic fracture mechanical properties of limestone after chemical corrosion," Theoretical and Applied Fracture Mechanics, vol. 108, p. 102620, 2020.

[11] F. Zhou, W. B. Sun, J. L. Shao, L. J. Kong, and X. Y. Geng, "Experimental study on nano silica modified cement base grouting reinforcement materials," Geomechanics and Engineering, vol. 20, pp. 67-73, 2020.

[12] X. Yang, D. Sun, and H. Jing, "Morphological features of shear-formed fractures developed in a rock bridge," Engineering Geology, vol. 278, p. 105833, 2020.

[13] S. Zhao, D. M. Zhang, and H. W. Huang, "Deep learningbased image instance segmentation for moisture marks of shield tunnel lining," Tunnelling and Underground Space Technology, vol. 95, pp. 1-11, 2020.

[14] S. Zhao, M. Shadabfar, D. M. Zhang, J. Y. Chen, and H. W. Huang, "Deep learning-based classification and instance segmentation of leakage-area and scaling images of shield tunnel linings," Structural Control and Health Monitoring, vol. 28, no. 6, pp. 1-22, 2021.

[15] J. Y. Chen, M. L. Zhou, H. W. Huang, D. M. Zhang, and Z. C. Peng, "Automated extraction and evaluation of fracture trace maps from rock tunnel face images via deep learning," International Journal of Rock Mechanics and Mining Sciences, vol. 142, pp. 1-16, 2021.

[16] S. Q. Yang and B. Hu, "Creep and long-term permeability of a red sandstone subjected to cyclic loading after thermal treatments," Rock Mechanics and Rock Engineering, vol. 51, no. 10, pp. 2981-3004, 2018.

[17] A. Keneti and B.-A. Sainsbury, "Characterization of strainburst rock fragments under a scanning electron microscope - an illustrative study," Engineering Geology, vol. 246, pp. 12$18,2018$.

[18] B. X. Liu, Z. L. Shu, J. J. Han, M. M. Liu, and K. Zhang, "Realtime CT experimental research on creep microscopic damage evolution of coal rock under compression," Disaster Advances, vol. 5, pp. 667-674, 2012.

[19] M. Kou, X. Liu, S. Tang, and Y. Wang, "3-D X-ray computed tomography on failure characteristics of rock-like materials under coupled hydro-mechanical loading," Theoretical and Applied Fracture Mechanics, vol. 104, p. 102396, 2019.

[20] X. X. Yang and W. G. Qiao, "Numerical investigation of the shear behavior of granite materials containing discontinuous joints by utilizing the flat-joint model," Computers and Geotechnics, vol. 104, pp. 69-80, 2018.

[21] V. Billault, D. Beaufort, A. Baronnet, and J.-C. Lacharpagne, "A nanopetrographic and textural study of grain-coating chlorites in sandstone reservoirs," Clay Minerals, vol. 38, no. 3, pp. 315-328, 2003.

[22] M. B. Gorji and D. Mohr, "Micro-tension and micro-shear experiments to characterize stress-state dependent ductile fracture," Acta Materialia, vol. 131, pp. 65-76, 2017.

[23] Y. Cheng and L. N. Y. Wong, "Microscopic characterization of tensile and shear fracturing in progressive failure in marble," Journal of Geophysical Research: Solid Earth, vol. 123, no. 1, pp. 204-225, 2018.

[24] T. Ai, R. Zhang, H. Zhou, and J. Pei, "Box-counting methods to directly estimate the fractal dimension of a rock surface," Applied Surface Science, vol. 314, pp. 610-621, 2014.

[25] R. Peng, Y. Yang, Y. Ju, L. Mao, and Y. Yang, "Computation of fractal dimension of rock pores based on gray CT images," Chinese Science Bulletin, vol. 56, no. 31, 2011.

[26] Z. Feng and X. Sun, "Box-counting dimensions of fractal interpolation surfaces derived from fractal interpolation functions," Journal of Mathematical Analysis and Applications, vol. 412, no. 1, pp. 416-425, 2014.

[27] Y. Gao, H. Jing, and Z. Zhou, "Fractal analysis of pore structures in graphene oxide-carbon nanotube based cementitious pastes under different ultrasonication," Nanotechnology Reviews, vol. 8, pp. 107-115, 2019.

[28] Y. Gao, H. Jing, Z. Zhou, W. Chen, M. Du, and Y. Du, "Reinforced impermeability of cementitious composites using graphene oxide- carbon nanotube hybrid under different waterto-cement ratios," Construction and Building Materials, vol. 222, pp. 610-621, 2019.

[29] G. Han, H. Jing, Y. Jiang, R. Liu, and J. Wu, "Effect of cyclic loading on the shear behaviours of both unfilled and infilled rough rock joints under constant normal stiffness conditions," Rock Mechanics and Rock Engineering, vol. 53, no. 1, pp. 31-57, 2020.

[30] M. Chen, S. Q. Yang, P. G. Ranjith, and Y. C. Zhang, "Cracking behavior of rock containing non-persistent joints with various joints inclinations," Theoretical and Applied Fracture Mechanics, vol. 109, p. 102701, 2020.

[31] B. Nigon, A. Englert, C. Pascal, and A. Saintot, "Multiscale characterization of joint surface roughness," Journal of Geophysical Research: Solid Earth, vol. 122, no. 12, pp. 97149728, 2017.

[32] N. Barton, "Review of a new shear-strength criterion for rock joints," Engineering Geology, vol. 7, no. 4, pp. 287-332, 1973.

[33] N. Barton and V. Choubey, "The shear strength of rock joints in theory and practice," Rock Mechanics, vol. 10, no. 1-2, pp. 154, 1977. 
[34] P. Kulatilake, J. Um, and G. Pan, "Requirements for accurate estimation of fractal parameters for self-affine roughness profiles using the line scaling method," Rock Mechanics and Rock Engineering, vol. 30, no. 4, pp. 181-206, 1997.

[35] T. Belem, F. Homand-Etienne, and M. Souley, "Quantitative parameters for rock joint surface roughness," Rock Mechanics and Rock Engineering, vol. 33, no. 4, pp. 217-242, 2000.

[36] Y. Li, J. Oh, R. Mitra, and B. Hebblewhite, "Experimental studies on the mechanical behaviour of rock joints with various openings," Rock Mechanics and Rock Engineering, vol. 49, no. 3, pp. 837-853, 2016.

[37] E. Kuhl, E. Ramm, and K. Willam, "Failure analysis of elastoplastic material models on different levels of observation," International Journal of Solids and Structures, vol. 37, no. 4850, pp. 7259-7280, 2000. 